\title{
An Integrated Damping System for Tall Buildings
}

\author{
M. Martinez-Paneda ${ }^{1}$ and A. Y. Elghazouli ${ }^{2}$ \\ ${ }^{1}$ Foster + Partners, Structural Engineering Group \\ ${ }^{2}$ Department of Civil and Environmental Engineering, Imperial College London
}

\begin{abstract}
This paper proposes an Integrated Damping System that aims at providing relatively high damping levels through the mobilization of a proportion of the structure's own mass. This offers significantly higher mass levels and, consequently, considerably more damping compared to conventional Tuned Mass Dampers. Fluid Viscous Dampers are used to control accelerations, in parallel with springs to resist the static loads applied to the moving mass. The advantages of employing relatively large mass levels in achieving considerable damping and reducing sensitivity to tuning are first analyzed using an idealized two-degree of freedom structural representation. This is then followed by a description of the proposed 'Integrated Damping System', which is illustrated through a case study of a $250 \mathrm{~m}$ tall building. The benefits of the proposed damping system are demonstrated through several numerical parametric assessments, as well as a selected suite of earthquake records. For the adopted case study, it is shown that, besides reducing the level of perceivable accelerations, the use of the suggested arrangement can offer an equivalent damping exceeding $50 \%$ of the critical damping, resulting in more than $40 \%$ reduction in the wind loads as well as over $60 \%$ reduction in displacement and acceleration response under seismic excitations.
\end{abstract}

Keywords: dynamic response; damping systems; passive damping; energy dissipation; multi-story structures; tall buildings.

\section{Introduction}

The benefits of employing supplementary damping systems in structures, in terms of achieving effective and reliable seismic design solutions, are being increasingly recognized. As opposed to using typical capacity design approaches in which inelastic deformations are accommodated within specific predefined dissipative structural regions, added damping techniques offer favorable low damage and seismically resilient alternatives. The merits of providing supplementary damping are clearly not limited to seismic design but may apply to other governing dynamic excitations, such as wind-induced response, particularly for tall buildings ${ }^{[1]}$.

Various types of damping systems have been developed over the years. One of the most common is the Tuned Mass Damper (TMD), due to its relative simplicity and adaptability to 
be added late in the design stage. Arguably, the first form of a TMD was that developed by Frahm in 1909 [2]. However, the first compiled theory of its behavior is that published by Ormondroyd and Den Hartog [3]. Since the first TMD was implemented in the John Hancock Tower in $1976^{[4]}$, significant additional related research has followed, and different types of TMD have been developed and adopted [4,5].

Several detailed studies [6-16] have focused on assessing the optimum parameters for the performance of TMD as well as Multiple Tuned Mass Dampers (MTMD) under wind and seismic loading conditions. However, although the ratio of the added mass of the TMD to that of the structure is the key parameter determining the performance, mass ratios of only 1 to $2 \%$ have typically been implemented as larger values would be unrealistic due to practical constraints [17]. To try to overcome this, several modified systems have been proposed such as the 'roof-garden TMD' [18], in which a heavy roof garden is located at top level and used as the mass of the TMD. A more developed alternative to this is the so-called 'mega-sub control system'. For a building with a mega-frame structure, the system proposes to create interior substructures that could dissipate energy either by having the interior structure vibrating in shear and hence enabling energy dissipation by conventional methods [19], or by having the substructure acting as the mass of a TMD [20-22]. By mobilizing a large portion of the own mass of the building, the system is hence capable of greatly improving the seismic performance of the building. However, since the stiffness of the damped mass of the TMD is tuned to enable the mass to behave as a TMD, the system cannot resist wind loads so it can only be applied to interior portions of the building, which greatly limits its application as well as its capability to mobilize a larger mass ratio. This also imposes a series of strict requirements on the contiguous structure to prevent pounding. A similar variation is the 'Suspended Slab System', based on a combination of MTMD in the form of Pendulum Tuned Mass Dampers and a Floor Isolation System (FIS) [23]. While the latter has the benefit of being able to mobilize part of the mass of the building as a hanging TMD mass, it also shares several of its limitations. For example, the requirement to duplicate the structure, as a conventional FIS and hence reducing flexibility, or the need to have all floors perfectly tuned, restricting it to just interior applications.

For tall buildings, since the first elastomeric viscoelastic dampers were used to control vibrations in the World Trade Center in 1969, research has focused on the contribution of these damping systems to resist seismic and wind-induced vibrations [24]. For the World Trade Center, damping was provided by 10,000 elastomeric dampers at each tower, joining the 
façade to the bottom chords of the floor trusses all along the building. Measurements showed that this arrangement provided 2.5-3.0\% additional equivalent damping. Several studies have proven the effectiveness of viscoelastic dampers for both wind and seismic excitations [25]. However, since viscoelastic dampers dissipate energy through heat and their properties are highly temperature-dependent, their use reduced as Fluid Viscous Dampers (FVD) were introduced.

A widely-reported example of the use of FVDs is the 57-story Torre Mayor building in Mexico, completed in 2003, which uses a total of 98 FVDs to reduce seismic effects. Some of the dampers span several floors, connected to mega-braces up to $20 \mathrm{~m}$ long. Several numerical studies were performed to verify the behavior of the proposed dampers under seismic loads [26]. In 2003, the tower was subjected to a 7.6 magnitude earthquake which demonstrated the effectiveness of the damping system [27]. Studies have also shown that FVDs can also be effectively used to reduce wind-induced vibrations, and they were used for this purpose in the 111 Huntington Avenue building in Boston. In this case, the system incorporated motion amplification devices (toggle bracing), achieving a level of damping of up to $3 \%$ of critical [28, 29]. Several other mechanisms have been proposed as an alternative to the toggle bracing arrangement in order to increase the relative motion between both ends of the FVD and thus enhance their performance ${ }^{[30]}$. FVD's performance is also conditioned by their location within the structure, since, for typical buildings, their optimum positions would correspond to the ones with the largest inter-story drifts ${ }^{[31]}$.

Departing from their conventional use in conjunction with diagonal members, and to take advantage of the full potential of FVDs, a proprietary 'Damped Outrigger' system [32, 33] was proposed by ARUP. The system was first implemented in two $210 \mathrm{~m}$ tall towers in the Philippines, an area prone to typhoon winds and seismic events. In this case, multiple Fluid Viscous Dampers are placed between an outrigger, which cantilevers from the core, and the perimeter mega columns. Energy is dissipated through the differential movement between the cantilevering outrigger and the perimeter columns as the building sways. While the use of FVDs has the advantage of not requiring frequency tuning, as FVDs have no linear stiffness, the outrigger cannot be used to resist static loads, and hence the stiffness of the tower is reduced when compared to the case of a fixed outrigger. A damping of up to $7.5 \%$ of critical was achieved for the 10-year wind scenario. For this application, due to the large damping coefficient of the FVD, and to avoid introducing excessive loads during an earthquake, a release valve had to be introduced within the FVD. Following its development, the Damped 
Outrigger system has been applied in several other tall buildings in recent years and several studies have been carried out towards further improvements and applications [35-38].

It is worth noting that, if a redundant damping system such as the Damped Outrigger is adopted, it is possible to consider the contribution of damping in reducing the response of the building to the dynamically-induced wind excitations and hence, considerably reduce the design lateral and overturning forces. As indicated in several previous studies [35, 39], this permits a significant reduction in the size of structural elements in both the superstructure and the foundations thus leading to considerable cost savings. In this respect, the benefits of adding damping to tall buildings have been demonstrated in various projects. For example, for 250 West $55^{\text {th }}$ Street in New York, by adding 2\% extra damping, accelerations were controlled and 1,000 $\mathrm{t}$ of steel were removed [32]. Another example is the two St Francis Shangri-La Place towers in Manilla, where a net saving of \$5M US was achieved through added damping ${ }^{[33]}$.

The research presented in this paper proposes a variation of the TMD system, referred to herein as the Integrated Damping System (IDS). The system aims to provide relatively high damping levels through the mobilization of a proportion of the own mass of the structure as the mass of a TMD. The IDS builds upon the formulation of TMDs, the 'mega-sub control system' as well as other similar systems, and proposes a novel arrangement starting from fundamental principles. It addresses the issue that while the requirement to have the damper mass of the TMD perfectly tuned to the optimum frequency maximizes its performance, it also imposes a major restriction on its practicality for design implementation and its ability to mobilize a significant mass ratio. Contrary to previous applications, the stiffness of the damped mass of the TMD is not proposed herein to be tuned to that required for the TMD, but to that required to control the movable mass motion under wind loads. While this variation changes the system behavior, it also drastically improves its versatility and allows for its application to all building types and for both interior and exterior cases, thus enabling it to mobilize a far larger mass ratio. Moreover, despite the reduction in performance of the TMD due to the lack of tuning in stiffness, the effective increase in the mass ratio allows the IDS to provide an even larger equivalent damping than it could be provided with a perfectlytuned smaller mass through either the 'mega-sub control system' or conventional TMDs. The proposed arrangement adopts a non-classically damped system which incorporates Fluid Viscous Dampers (FVD), to control accelerations and dissipate energy, in parallel with springs to resist the static loads applied to the moving mass of the structure. The proposed 
arrangement is particularly suited for tall buildings, but it could also be adopted in other structural configurations. The fundamental concept is to utilize the movement of the structure, in conjunction with a significant proportion of the own weight, to provide significant damping. The fact that the IDS system is integrated within the building, without the need to occupy several floors, disrupt the floor plan or add extra mass, is the reason for the choice of its name.

In subsequent sections, the benefits of employing relatively large mass levels in TMD systems in achieving considerable damping and reduced sensitivity to tuning is firstly investigated using a fundamental treatment of an idealized two-degree of freedom structural representation subjected to main mass as well as base excitations. This is then followed by a description of the proposed 'Integrated Damping System (IDS)', which is illustrated through a case study of a $250 \mathrm{~m}$ tall building. The benefits of the proposed IDS in significantly reducing the dynamic response are demonstrated through several numerical parametric assessments using sinusoidal and white noise functions and a selected suite of earthquake records.

\section{Large-Mass Tuned Mass Dampers}

\subsection{Conventional approaches}

The current typical approach for tall building design is to first meet the stiffness and strength requirements, and then, if the acceleration limit is not met, either provide additional lateral stiffness and strength, or introduce additional damping such as through an added mass at the top. As noted before, mass dampers originated from the vibration absorber system proposed by Ormondroyd and Den Hartog [3], which was originally used to reduce mechanical vibrations. It is based on the idea of adding a mass with a spring and a damper in parallel to a structure to reduce its dynamic response. The vibration amplitude is reduced by introducing equal and opposite dynamic forces and/or by dissipating energy through a damper [40].

TMDs are tuned to a particular frequency to increase the dissipation energy at that frequency. With a mass ranging typically from 0.5 to $1.0 \%$ of that of the building, they usually provide an equivalent damping of $2-4 \%$ of the building critical damping. In addition to the practical limits on the level of added mass, and hence damping, that can be provided, conventional TMDs can have several drawbacks including: (i) some large usable space is occupied by the added mass at the top of the building; (ii) the structure may have to be strengthened up to resist the additional mass, e.g. $730 \mathrm{t}$ for the Taipei 101 TMD [4]; (iii) specific frequency tuning 
is more suited for wind rather than seismic excitation due to significant higher modes; (iv) sensitivity to detuning can result in significant loss in performance; and (v) it cannot be typically used for reducing wind-induced design loads due to lack of redundancy, resulting from maintenance or repair issues, or detuning due to changes in natural period with time [32, 35].

Several previous studies have pointed out that optimally designed TMDs are not suitable for resisting seismic loads due to their ineffectiveness when responding to pulse excitations, and their inability to reach a resonant condition under random base-excitations [41, 42]. It has been reported that actual structures incorporating TMDs designed to control wind-induced vibrations have suffered damage due to response in higher modes [44]. To overcome this limitation, some researchers have investigated the combination of conventional TMDs with friction devices leading to an improved performance to pulse excitations [45-49]. Moreover, to counteract the sensitivity of a TMD to a fluctuation in the natural frequency of the structure or in the damping ratio of the TMD, other researchers have explored the use of Multiple Tuned Mass Dampers (MTMD). These are designed to cover a range of frequencies around the fundamental mode. Results have shown that if a small range is set, the performance of the MTMD can be more robust than that of a conventional TMD [17, 43, 50].

To overcome the limitations of conventional passive TMDs, numerous alternatives have been proposed and investigated within recent years [51-53]. Still within the passive range, a big research effort is now being directed towards nonlinear dissipative systems such as Nonlinear Energy Sinks and especially Particle Impact Dampers (PID) or its recent variation of Particle Tuned Mass Dampers (PTMD) [54]. While PIDs have been widely used in aerospace and mechanical industries, it is not yet that common within civil engineering. This is partly due to its high non-linear behavior that complicates its design and assessment, and, despite its capacity to be effective over a broad range of frequency, overcoming one of the main drawbacks of conventional TMDs, also due to its relatively reduced efficiency for short frequency excitations, which is partly overcome by the PTMD system [55-57]. Moving beyond passive schemes more advanced systems have also been widely investigated and already have some practical applications. These are active, semi-active and hybrid systems [58]. While active systems can effectively mitigate most of the disadvantages of conventional TMDs, with considerable recent improvements in their control algorithms to improve their response [59-67], they typically result in a higher cost and require a large source of external power, which makes them less reliable and practical. To overcome this last detriment, semi-active systems are 
devised to require only a minimum amount of external energy. Moreover, as a further natural step towards improving their reliability, hybrid arrangements are also being proposed. These are typically a combination of an active or semi-active system and a passive one [68, 69]. A good summary of recent advances in the field can be found in the papers by Fisco and Adeli [70, 71]. Yet, while research is advancing to improve the cost-effectiveness and performance of these systems, passive systems are still most widely used within the industry due to their reduced cost, good performance and larger reliability despite their aforementioned detriments.

\subsection{Idealized representation}

The possibility of using part of the own mass of the building as the mass of the TMD not only avoids occupying any floor space or increasing the structural elements to resist the added mass, but also has the advantage that a significantly larger mass than normal can be used. To explore the benefits of using a significantly larger mass, the behavior of a TMD is examined using a 2DOF idealized representation where the main structure is represented as a SDOF and the TMD is attached to it. The adequacy of the simplification of using a TMD attached to a SDOF to represent its behavior has been verified by several researchers $[7,42]$, provided that the main natural frequencies are adequately separated, which is generally the case for tall buildings. To ensure its accuracy, the ratio between the two fundamental frequencies, $\frac{f_{2}}{f_{1}}$, should be less than 2 , or 3 depending on the value of the mass ratio, $\mu$ [7,72].

Although detailed parametric assessments (e.g. ${ }^{[7]}$ ) indicate that the mass ratio, $\mu$, is the main parameter influencing the performance of TMDs, these studies do not typically extend to ratios beyond 10\% due to the practical limits of providing such high levels of added mass. However, as the proposed system, which is described in subsequent parts of this paper, employs the own mass of the building, a significantly larger mass ratio can be realized.

The concept of the tuned mass damper is illustrated with an idealized 2DOF where a TMD is attached to a SDOF that represents the main structure (Figure 1). The response of such a system has been examined by several researchers [8,9,42]. The governing equations of motion divided by their mass are:

$$
\begin{gathered}
\text { Primary mass: } \quad(1+\mu) \ddot{\mathrm{u}}+2 \xi \omega \dot{\mathrm{u}}+\omega^{2} u=\frac{p}{m}-\mu \ddot{\mathrm{u}}_{d} \\
\text { Tuned mass: } \ddot{\mathrm{u}}_{d}+2 \xi_{d} \omega_{d} \dot{\mathrm{u}}_{\mathrm{d}}+\omega_{\mathrm{d}}^{2} u_{d}=-\ddot{\mathrm{u}}
\end{gathered}
$$


in which $\mathrm{m}, \mathrm{k}, \xi$ and $\omega$, are, respectively, the mass, stiffness, damping ratio and natural frequency of the main structure. The damped mass properties are defined by the " $\mathrm{d}$ " subscript, and $\mathrm{p}$ represents a periodic excitation defined as:

$$
p=P \sin \Omega t
$$

The mass ratio $\mu$ is defined as:

$$
\mu=\frac{m_{d}}{m}
$$

The damping ratio $\left(\xi_{\mathrm{d}}\right)$ of the TMD is defined as the optimum value for the case of the main mass subjected to a harmonic excitation:

$$
\xi_{d, o p t}=\sqrt{\frac{3 \mu}{8(1+\mu)}}
$$

The damper is tuned to the fundamental frequency of the main mass:

$$
\omega_{d}=\omega
$$

This defines the stiffness of the damped mass as a function of its mass ratio. The response is thus given by:

$$
\begin{aligned}
& u=U \sin \left(\Omega t+\delta_{1}\right) \\
& u_{d}=U_{d} \sin \left(\Omega t+\delta_{1}+\delta_{2}\right)
\end{aligned}
$$

where $\mathrm{P}$ and $\mathrm{U}$ represent the amplitude of the motion. For the resonant condition, which represents the critical loading: $\Omega=\omega$, the amplitude of the solution is defined as:

$$
U=\frac{P}{k \mu} \sqrt{\frac{1}{1+\left(\frac{2 \xi}{\mu}+\frac{1}{2 \xi_{d}}\right)^{2}}}
$$

Based on this, and considering $\xi_{\mathrm{d}}$ as the optimum damping from Equation (4), the equivalent damping $\xi_{\mathrm{e}}$ (which represents the relative contribution of the damper parameters normalized by total damping), can be determined as:

$$
\xi_{e}=\frac{\mu}{2} \sqrt{1+\left(\frac{2 \xi}{\mu}+\frac{1}{2 \xi_{d}}\right)^{2}}
$$

It should be noted that a closed-form solution cannot be obtained for the optimum parameters if there is damping in the main mass [6, 42]. Nonetheless, as shown for both harmonic [6] and random excitations [7], the effect of having light damping in the main mass on the optimum 
parameters is very small. Since for tall buildings the intrinsic damping is relatively low, it can be set to zero. Consequently, setting the damping ratio of the added mass as the optimum (Equation 5), the relationship between the mass ratio $\mu$ and the equivalent damping $\xi_{\mathrm{e}}$ can be represented as depicted in Figure 2. As expected, it is observed in the figure that the equivalent damping obtained can be greatly enhanced by providing a large mass ratio.

Another key parameter is the relative motion between the TMD and the main structure. From simple rearrangement of the above-presented equations, the ratio of the maximum displacement amplitudes of the damped mass and the main mass $\left(U_{d} / U\right)$, for a specific level of equivalent damping, can be determined as follows:

$$
\frac{U_{d}}{U}=\sqrt{\left(\frac{2 \xi}{\mu}\right)^{2}-1}
$$

The above relationship is depicted in Figure 3, for a series of target equivalent damping values. From the results it is evident that as the mass ratio $\mu$ increases, the required relative displacement between both masses decreases for a given value of $\xi_{\mathrm{e}}$.

The main conclusion from Figures 2 and 3 is that, if a large enough mass is mobilized, a considerable amount of equivalent damping can be obtained with minimum relative movement. This encapsulates the main concept behind the integrated damping system that will be put forward in this investigation.

\subsection{Harmonic response}

To explore the behavior of large-mass TMDs it is useful to consider the behavior of conventional TMDs (Figure 1) from first principles and to compare it to that of a continuously damped structure, i.e. a structure in which all significant DOFs are damped (Figure 4). In both systems, energy is dissipated through the differential movement and velocity of the two ends of the dampers. However, in conventional TMDs the energy that is dissipated in the dampers is very small due to their reduced relative mass, thus their contribution in reducing the overall response mostly comes by introducing a force that opposes the movement of the structure. To introduce this force, the damped mass of the TMD has to move opposite to the building's movements and thus needs to be tuned to its main natural frequency. On the other hand, a continuously damped structure makes use of having all the mass connected to dampers to provide damping only by the differential movement of their ends and not creating any opposite forces. This has the significant advantage that it does not require tuning up to a specific mode. Based on this, it is possible to see that as the TMD mass increases its behavior 
will approach that of a continuously damped structure at the point where the mass ' $\mathrm{m}$ ' approaches zero. Consequently, even if it is not damped, the excitation of the mode which would involve ' $m$ ' will have a negligible impact on the structure.

To examine how the system shifts from the behavior of a continuously damped system to that of a TMD, the SDOF system with an attached TMD used in Section 2.2 above is employed (Figure 1), following the same idealizations adopted in previous studies [8]. The response of the system is assessed herein for ground and main mass (' $\mathrm{m}$ ') harmonic excitations with a ratio of the excitation frequency to the main mass natural frequency, (' $r$ '), ranging from 0 to 2 . Under a harmonic excitation, the response ratio of the main mass is defined as:

$$
\begin{aligned}
\frac{U}{U_{s t}} & =\frac{\sqrt{\left(1+\Delta \mu-\frac{r^{2}}{f^{2}}\right)^{2}+4\left(\frac{\xi_{d} r}{f}\right)^{2}(1+\Delta \mu)^{2}}}{Z} \\
Z & =\left\{\left[\frac{r^{4}}{f^{2}}-\frac{r^{2}}{f^{2}}-r^{2}(1+\mu)-4 \frac{\xi \xi_{d} r^{2}}{f}+1\right]^{2}+\left[2 \frac{\xi r^{3}}{f}+2 \frac{\xi_{d} r^{3}}{f}(1+\mu)-2 \frac{\xi_{d} r}{f}-2 \xi r\right]^{2}\right\}^{\frac{1}{2}}
\end{aligned}
$$

where:

$\Omega \quad$ Natural frequency of the periodic excitation

$U_{s t}=\frac{P}{K} \quad$ Displacement of main mass under static load of magnitude P

$\Delta= \begin{cases}1 & \text { for ground excitation } \\ 0 & \text { for main mass excitation }\end{cases}$

$r=\frac{\Omega}{\omega} \quad$ Ratio of excitation frequency to main mass natural frequency

$f=\frac{\omega_{d}}{\omega} \quad$ Frequency ratio damper mass - main mass

The system assumes that intrinsic damping is relatively low $(\xi=1 \%)$, as it would be the case for a typical tall building, and that both the damping ratio and frequency of the damped mass of the TMD are optimum; i.e. corresponding to the smallest peak response. For the main mass excitation, the optimum damping was defined before (Equation 5), and the optimum frequency ratio can be determined as:

$$
f_{\text {opt }}=\frac{1}{1+\mu}
$$

For the ground excitation, the respective values of the frequency and damping ratios are set as: 


$$
\begin{gathered}
f_{\text {opt }}=\frac{1}{1+\mu}\left(\sqrt{\frac{2}{2-\mu}}\right) \\
\xi_{d, o p t}=\sqrt{\frac{3 \mu}{8(1+\mu)}}\left(\sqrt{\frac{2}{2-\mu}}\right)
\end{gathered}
$$

The amplitude of the steady-state response of the system is compared for different mass ratios $\mu$ in Figure 5 (a) for main mass harmonic excitation and Figure 5 (b) for ground harmonic excitation. From the figures, a number of observations can be made: (i) as expected, the steadystate amplitude $\left(\mathrm{U} / \mathrm{U}_{\mathrm{st}}\right)$ of the main mass decreases with the increase in $\mu$; (ii) for low values of $\mu$, the response degrades rapidly as the input frequency ratio $\mathrm{r}$ deviates from unity; (iii) for a relatively high $\mu$, the response becomes less sensitive to the resonance effect and, as a result, the large-mass TMD can control the response for a wider range of excitation frequencies; (iv) as $\mu$ increases, the frequency ratio at optimum damping shifts from unity towards a lower value as the mass distribution varies.

From the above-noted observations, the ability to mobilize a relatively large mass ratio would overcome many of the limitations of conventional TMDs. Importantly, it results in reduced sensitivity to changes in the frequency of the system, hence providing a more robust response. Moreover, it enables control of the system response in higher frequency modes, thus becoming suitable for dealing with both wind and seismic loads. However, the idealization of a SDOF with an attached TMD clearly disregards the contribution of the higher modes to the response, hence verification would be required for the effects of higher modes in actual structures.

\subsection{Optimum parameters}

To magnify energy dissipation, conventional TMDs have to be tuned up to the dominant natural frequency of the structure. As this is the key consideration for TMD systems, several procedures have been developed to obtain the optimum parameters for a variety of input excitations [17]. If the parameters move away from their optimum, the response of the system will degrade. This deviation in the parameters is referred to as detuning. Detuning imposes a significant disadvantage in tuned mass dampers since as soon as the damped mass of the TMD, the stiffness of the springs, the properties of the dampers, or the frequency of the building change, the response of the system will degrade. 
The two parameters that are investigated herein, and that will determine the tuning of the system, are the frequency ratio between the frequency of the damped mass of the TMD and the frequency of the main mass, $\mathrm{f}$, and the damping ratio of the TMD mass, $\xi_{\mathrm{d}}$, for both ground and main mass excitations. For the main mass excitation, to investigate the effect of detuning on the frequency ratio, the optimum damping is used as defined before (Equation 5). To investigate the effect of varying the damper coefficient of the damped mass of the TMD, the frequency ratio is set at its optimum value (Equation 14). For the ground excitation case, the respective optimum values of the frequency ratio and the damping ratio are set as previously defined (Equations $15 \& 16)$.

Detuning of the frequency ratio is investigated for the case where the excitation frequency matches the main mass frequency (i.e. $r=1)$, assuming a relatively low intrinsic damping $(\xi=1$ $\%$ ) (see Figures $6 \mathrm{a}$ and $6 \mathrm{~b}$ for the main mass and ground excitations, respectively). The detuning effect of the damping ratio of the TMD mass is investigated by extracting the peak response of a system with a varying $r$ ratio, from $r=0$ to $r=2$, for the dimensionless ratio of the TMD mass damping ratio to its optimum value $\left(\xi_{\mathrm{d}} / \xi_{\mathrm{d}, \mathrm{opt}}\right)$, and for different mass ratios, $\mu$ (see Figure $7 \mathrm{a}$ for the main mass excitation, and $7 \mathrm{~b}$ for the ground excitation).

The results in Figures 6 and 7 show that the effect of detuning, in both $\mathrm{f}\left(\omega_{\mathrm{d}}\right)$ and $\xi_{\mathrm{d}}$, reduces with the increase of the mass ratio $\mu$. This is especially noticeable for the frequency ratio, $\mathrm{f}$, which indicates that the response of the system is considerably more sensitive to detuning on the frequency in comparison with the damping ratio. These conclusions match those obtained by Rana \& Soong $[8]$, where it is observed that for large mass ratios the performance of the system is no longer so highly dependent on detuning as in a conventional TMD.

\section{Integrated Damping System}

\subsection{Proposed arrangement}

The Integrated Damping System proposed in this paper is based on the premise of using the own mass of the building as the damper mass. The proposed system utilizes the own mass of the structure, in conjunction with the structural movements, to obtain considerable damping levels whilst enabling the control of accelerations for serviceability purposes. As long as the accelerations of the building are controlled, the movements may not be a limiting condition from the point of view of human perception [73]. To increase the equivalent damping, instead of adding mass, a proportion of the own weight of the building is used as the mass of the 
TMD. This implies that part of the building would be moving differentially from the other. However, as it was shown before it is worth noting that, as the damper mass increases, large levels of additional damping can be generated with relatively small movements. Nonetheless, in order to enable control of serviceability accelerations, Fluid Viscous Dampers (FVD) are employed within the connections of the damping mass to the rest of the building.

As the moving part of the building has to resist the mean wind load acting as a static load, unless wind loads are resisted by other means, adequate stiffness has to be provided due to the inability of FVDs to provide static resistance. This stiffness, which is represented as a spring acting in parallel with the FVDs, can be provided either by a separate structural member providing horizontal stiffness or by a spring implemented within the FVD, as adopted in previous retrofitting studies [74]. The stiffness of the spring also determines the degree of relative movement between both parts of the building, hence it has a direct influence on the achieved level of supplementary damping of the system.

Assuming that the intrinsic damping for the rest of the structure is comparatively insignificant, the system can be represented by a damper mass attached to a SDOF structure as in Figure 1. The behavior of the system, with a spring in parallel with the damper, resembles that of an elastomeric viscoelastic damper. It should be noted that whilst the use of elastomeric viscoelastic dampers was initially considered, this was discarded. Apart from their temperature-dependent properties and lower damping compared to FVDs, they were unable to adequately control serviceability accelerations.

In principle, the Integrated Damping System originates from the idea of a large-mass TMD and the mega-sub control system. However, as its name implies, tuned mass dampers have to be tuned up to effectively reduce the response. For the proposed system this raises a critical issue since all key properties have a relatively limited range. The stiffness of the damper mass, $\mathrm{k}_{\mathrm{d}}$, has a lower bound as it requires to be stiff enough to provide restraint to the mass and control its maximum displacements under static loading. The frequency, $\omega_{\mathrm{d}}$, is also controlled by the mass and the stiffness, where for a general case the mass should be as large as possible. Moreover, the damping ratio of the damper mass, $\xi_{\mathrm{d}}$, is defined by the damper coefficient of the FVD which provides damping and controls the accelerations of the mass. From a first approach this would deem the performance of the proposed system unacceptable. However, as noted ${ }^{[8]}$ and investigated in Section 2.4 before, if a large enough mass ratio, $\mu$, is used, the system no longer requires to be tuned to its optimum parameters in order to effectively reduce the response. 


\subsection{Practical implementation}

The concept behind the IDS was conceived by re-examining the first principles of TMDs with the aim of extending it to a wide range of building configurations. By allowing the movable mass to resist wind loads, it was possible to move away from the mega-frame configuration, to which the 'mega-sub control system' is restricted, and apply it to any tall building typology. This is illustrated in Figure 8 for a building with a central core, arguably the most common typology for tall buildings. As indicated, the idea for the system would be to have the core providing the lateral stability of the building and have a movement joint between the core and the floor plate to enable the floor plate to move independently. The floor structure is then connected to the core with FVDs in parallel with springs that provide the in-plane stability of the floor and control its movements under either wind or seismic loads in order to meet the performance requirements. The columns that support the floor plate can be detailed as continuous elements that do not take any part in the lateral stability or as pin-ended elements to enable the floor, acting as mass of the TMD, to move with respect to the core. Moreover, as shown in Figure 8, the IDS can provide damping not only in the translational modes, but also in the torsional mode which is often significant, and which several standard damping approaches are typically ineffective in mitigating.

After considering first principles and various potential applications, the use and performance of the IDS was investigated for an illustrative $250 \mathrm{~m}$ tall building for which the system was considered. Due to the desire to have column-free office space and the vertical communication cores situated at the boundaries, an office floor volume was created as independent from the cores (see Figure 9). With its four vertical communication cores situated at the corners, the lateral resisting system was that of a mega-frame involving five sets of $12 \mathrm{~m}$ deep trusses connecting the four cores (see Figure 10). These trusses were also used to collect gravity loads from the office floors, and thus divide the tower into 5 independent vertically-stacked blocks. Each block cantilevers from the central square alternately in two orthogonal directions (see Figure 11).

The tower was designed as a composite structure with L-shaped reinforced concrete cores at the corners. The trusses and the secondary structural elements were designed as a steel system with composite floors. The office blocks were designed using simple construction, with pinned connections, such that the lateral stability of every floor is provided by diaphragm action between the composite deck and the cores. Due to the requirement of having an open plan, the office space could be defined as an independent volume from the cores (see Figure 
12), which represent the primary lateral resisting system. This arrangement raised the idea of exploring the potential damping that could be obtained by enabling a small differential movement between those two parts of the building.

For the proposed Integrated Damping system, as the office block has to resist the static wind load and control the accelerations, a spring is used in parallel with a Fluid Viscous Damper on every floor (see Figure 13). Due to the orientation of every office block (either N-S or E-W), it was decided that only the top two office blocks would be moving differentially and that each of them would move in one direction only. By the combination of those two motions, it is thus possible to ensure that the tower will generate additional damping in all directions while maintaining a relatively simple system. Nonetheless, the system offers various possible variations and, for example, for other applications, all office blocks can be defined as movable and thus have them all generating damping. This could be highly beneficial for relatively high seismicity situations. To enable movement, a sliding joint is located between the office floor and the core at every level. This enables movement and allows the transversal wind forces to be transferred directly to the cores by bearing through the sliding joints (see Figure 14).

Vertical stability of the office block is ensured by having the trusses fixed to the cores, so that, in the movable office blocks, only the floors above the trusses will move differentially (see Figure 15) with the lateral stability being provided in-plane for every floor. To avoid fatigue issues the columns were designed with a physical pinned connection at truss level. For the current application it was decided to have the columns running as continuous elements and have a linear displacement distribution, but it would have also been possible to concentrate all the inter-story drifts in one or more storys instead of spreading them uniformly into the whole office block, resulting in a higher average to maximum floor motion ratio that could enhance the performance of the system. It is worth noting that although a potential application of the system is illustrated in the current investigation, there is a large number of possible variations and implementations that, not only increase the versatility of the system but could also lead to a higher performance.

The Integrated Damping System dissipates energy through the differential movement of the two ends of the FVDs. However, as its behavior combines that of a perfectly tuned TMD with that of a continuously damped structure, an even further reduction in response could be provided by adjusting the spring to match the fundamental natural frequency of the building. In a conventional TMD, due to its small relative mass, tuning is the key requirement for the system to reduce the response. In contrast, due to the large mobilized mass, even if the 
proposed system is not tuned up to the frequency of the building, damping will be provided as long as there is differential motion. This has the significant advantage that the system will provide damping in all modes independently of the frequency of the building, hence being insensitive to changes in the properties of the building or the dampers. However, it should be noted that the maximum damping will occur at the maximum differential motion, hence the stiffness of the spring, and the way in which it restrains movement, plays a major role in determining the amount of equivalent damping that can be obtained. In contrast with a conventional TMD, and in addition to the previous benefits, as the system has several dampers at each floor, it can be assumed to be a redundant system and the additional equivalent damping that is generated can be used in the strength design to reduce the design wind loads.

\section{Parametric Assessment}

To determine the amount of equivalent damping that can be achieved with the proposed system, and to examine the influence of key parameters, a simplified model of the tower is employed in this section. In the adopted model, the trusses and the cores are represented with their respective stiffness, and each office block is considered as a lumped mass at its center of gravity (Figure 16). It is accepted that the response of tall or supertall buildings cannot be fully captured by a model that only looks at the response in one direction, but rather both horizontal directions should be investigated in order to acknowledge torsional or coupling effects due to excitations in the different directions ${ }^{[42]}$. However, only one lateral direction is considered in the current study to simplify the analysis by avoiding interference of other parameters in the predicted results and set the foundations for future more detailed analysis. The mass of the office blocks is based on only Dead and Superimposed Dead Load. The simplified model incorporates an intrinsic damping of $1 \%$ of critical to represent the tower's intrinsic viscous damping without the system.

With a damper exponent, $a$, equal to 1 , the performance of the system is controlled through changing the damper coefficient, $c_{d}$, and the spring stiffness, $k_{d}$. The damper coefficient, $c_{d}$, determines the opening arrangement within the damper. The higher this value is the larger the forces, $\mathrm{F}$, that will be transferred by the damper according to the following rule: $\mathrm{F}=\mathrm{c}_{\mathrm{d}} \mathrm{Va}$, where $\mathrm{V}$ is the stroke velocity of the damper. For example, for the Stockton Hotel building, the value used was $c_{d}=35,000 \mathrm{kNs} / \mathrm{m}{ }^{[74]}$ and for the 111 Huntington Avenue Tower, $c_{d}=53,000$ 
$\mathrm{kNs} / \mathrm{m}$ was used [29]. It is also worth noting that, as the simplified model only contains two dampers, the damper coefficient value that is considered corresponds to half of the sum of all damper coefficients along the office bock, as they work in parallel provided that the system moves as a single element. Apart from that, as the system has a spring in parallel with the damper, the stiffness of the spring, $\mathrm{k}_{\mathrm{d}}$, determines the amount of relative displacement that occurs between both ends. The softer the spring is, the larger the displacements, and hence velocities, and the larger the damping generated. Two extreme cases of relatively small movements and relatively large movements are considered in the current assessment.

\subsection{Loading conditions}

To determine the system behavior and, in particular, the additional equivalent damping that could be achieved, the idealized structure was modeled using the finite element program SAP20000 [75]. As the FVDs are velocity-dependent devices, and the resulting system is nonclassically damped, nonlinear analysis was necessary. Accordingly, nonlinear Time-History Analysis was performed for every analysis using direct integration. The additional equivalent damping of the structure was investigated in the first mode, which typically governs the design of tall buildings under wind loads, using the half-power bandwidth method. A sweep excitation was performed within a defined frequency range to obtain the peak response for every input frequency and damping coefficient. Following the procedure described in [76], it is possible to obtain the equivalent damping as follows:

$$
\xi_{e}=\sqrt{0.5-\sqrt{0.25-0.0625\left(\frac{f_{b}-f_{a}}{f_{n}}\right)^{2}\left(\frac{f_{b}+f_{a}}{f_{n}}\right)^{2}}}
$$

Where $f_{b}$ and $f_{a}$ are the forcing frequencies with an amplitude $1 / \sqrt{ } 2$ times the resonant amplitude, at each side of the resonant frequency, $\mathrm{f}_{\mathrm{n}}$.

To examine the performance of the Integrated Damping System under realistic earthquake loading, seven real earthquake acceleration time-histories were employed. The records were selected to match closely the EN1998-1 Type 1 Soil C target spectrum [77], minimizing the root mean square deviation, $D_{\text {RMS }}$, over a period range from $0.2 \mathrm{~s}$ to $7.0 \mathrm{~s}$, with a magnitude, $\mathrm{M}$, from 5.0 to 7.5 , a distance from the fault from 10 to $100 \mathrm{~km}$ and a shear wave velocity, $\mathrm{V}_{\mathrm{s}}$, from $180 \mathrm{~m} / \mathrm{s}$ to $800 \mathrm{~m} / \mathrm{s}$. All response spectra were scaled to match closely the EC8 spectrum with a Peak Ground Acceleration, PGA of 0.25 g. Figure 17 depicts the response spectra of the selected records together with the EC8 design spectrum [77]. Each record is referred to by its 
number in the NGA earthquake database, with the seismological data, scaling factors and corresponding $\mathrm{D}_{\mathrm{RMS}}$ values, as given in Table 1 . The respective acceleration-time histories are depicted in Figure 18 (a to g).

\subsection{Small differential displacements}

As a first approach, the stiffness of the spring at every floor is selected to allow a maximum movement of $25 \mathrm{~mm}$ under the 50-year return period EN1991-1-4 [78] 10 min mean wind load applied as a static load. A parametric study is performed in each analysis to determine the optimum damper coefficient of the FVD to maximize the equivalent damping, for this specific case. The performance improvement of the system is clearly seen in Figure 19 where the response of the Integrated Damping System to the sweep excitation is plotted against that of a conventionally fixed top office block. The equivalent damping that can be obtained for this case is then plotted in Figure 20 for a wide range of damper coefficients. From these results, it is possible to see that, for a maximum differential displacement of $25 \mathrm{~mm}$, and accounting for the $1 \%$ of intrinsic damping with which the tower was modeled, it is possible to achieve an additional equivalent damping of $1.9 \%$.

When the simplified model is analyzed using the 7 acceleration-time histories, it is shown that the level of improvement in the response compared to the fixed case varies from one case to another depending on the earthquake characteristics. As an example of the typical response, the top displacement of the optimum damper coefficient is plotted against the fixed option in Figure 21 for the $00302 \mathrm{~T}$ record. By calculating the average of the reduction in the top displacement for the 7 records, it can be shown that the Integrated Damping System can provide a maximum reduction in the top displacement of the tower of up to $30 \%$ with an average of $15 \%$ (Figure 22). As indicated before for conventional TMD, it is also the case for the IDS that the optimum damper coefficient to maximize the equivalent damping and thus improve the response is slightly different for wind (main mass excitation) and seismic (base excitation). Nonetheless, as the values of the damper coefficient obtained for each case are relatively small compared to other practical applications, it is reasonable to assume that the forces induced by the FVD would not be a controlling parameter in the design of the Integrated Damping System.

From the previous results, it is evident that for a very small displacement, by adding an Integrated Damping System it is possible to obtain the same additional damping as with a 
conventional Tuned Mass Damper without its drawbacks. The system can resist seismic loads and reduce the wind loads accounting for the redundant damping.

\subsection{Large differential displacements}

A softer spring is also investigated to illustrate the case where the building could accommodate larger displacements. For this case the spring stiffness is set to allow a maximum of $250 \mathrm{~mm}$ differential displacement under the 50-year return period mean wind load of Eurocode 1 [78], as for the previous case.

As it can be observed in Figures $23 \& 24$, the results show that the performance of the system improves drastically achieving an equivalent damping of up to $55 \%$.

The seismic response of the system also improves significantly when compared to the previous case of small differential displacements, yet this improvement again depends on the earthquake characteristics of the selected records. As a sample to illustrate the behavior, the top displacement of the optimum damper coefficient is plotted against the top displacement of the fixed option in Figure 25 for the $00138 \mathrm{~L}$ record. As shown in Figure 26, accounting for the response in the 7 acceleration-time histories it is shown that the IDS can provide a maximum reduction of displacements at the top of the tower of up to $67 \%$ with an average of $47 \%$ for the seven selected seismic excitations. These results are in agreement with expected damping in higher modes which, although not as significant as in the fundamental mode, can contribute up to $60 \%$ of that in the first mode, depending on the value of the damper coefficient.

\subsection{Acceleration control}

The proposed Integrated Damping System is based on the premise that through the use of Fluid Viscous Dampers, accelerations of the damper mass can be controlled. To assess the typical levels of acceleration of the tower when compared to those of a conventional fixed tower, the simplified model described before is subjected to a series of time-history analyses with three different type of input actions which are considered to represent extreme scenarios: (i) a uniform wind pressure applied to the office blocks following a sinusoidal function with a period matching the period of the structure, (ii) a uniformly applied wind load following a random white noise excitation over a mean of three-quarters of the static wind load based on Eurocode 1 provisions [78] (Figure 27) and (iii) the seven earthquake records defined before. The sinusoidal and the white noise excitations are applied as they are considered as the two extreme cases of narrow-band and wide-band excitations. It should be noted that to ensure 
that the FVD can control the accelerations they should have a high non-linear stiffness; this is to ensure that the shaft of the damper does not deform excessively during normal behavior.

The damper coefficient is the other key parameter that affects the accelerations. The reduction of the peak acceleration of the damped floors to those of the case when the floor is fixed is depicted in Figure 28 for the sinusoidal function, in Figure 29 for the White Noise excitation and in Figure 30 is as the average for the 7 earthquake records. To illustrate the behavior under all cases, the accelerations are assessed for the lower and upper bounds (small and large displacements). From the results it is shown that: (i) for the uniform wind loading following a sinusoidal function it is shown that the accelerations in the damped office block are higher than in the case of a fixed office block until the damper coefficient is equal or greater than $12,500 \mathrm{kNs} / \mathrm{m}$, where they start to reduce gradually; (ii) for the uniform wind loading following a white noise excitation, the accelerations are reduced for all cases; and (iii) for a seismic event, the accelerations are greatly reduced, as expected, as the office block mass is being effectively isolated from the accelerations of the frame by the FVD. Moreover, it should be noted that the optimum damper coefficient for acceleration control might not always match that for top displacement control. While the two parameters are related and within the same order of magnitude, a designer might choose to optimize one or aim for a balance between them in order to improve the system performance depending on each specific scenario. Interstory drift demands also need to be verified in specific cases, as the use FVDs to mitigate maximum acceleration response may enhance the contribution of higher modes.

From these results, it can be observed that if the damper coefficient is above a specific limit, the accelerations will not increase but rather reduce in the office block floors. However, it should be noted that while the damper coefficient controls the size of the openings in the damper and hence the speed at which the mass moves by creating an opposing force, there are other factors that also impact the level of accelerations for a given excitation. An example of those could be the building's damping or the one the IDS is able to generate. As expected, for the same excitation, an IDS configuration able to generate a larger additional damping would also typically result in a lower level of accelerations all across the building than a less efficient one would. Each application should typically be examined under a wind-tunnel test, yet it is evident that through the use of FVDs the acceleration levels can be effectively controlled, indicating the suitability of the Integrated Damping arrangement. 


\subsection{Overall performance}

The above-presented results show that the proposed system is able to control the accelerations of the damped mass and provide a large amount of additional reliable damping. The amount of additional damping that the system can generate is directly related to the stiffness of the springs which control the amount of differential displacement that the tower can accommodate. It is useful to illustrate the relationship between the additional equivalent damping that is generated against the relative displacements of the office block that are enabled under the EN1991-1-4 50-year wind load [78]. This is shown in Figure 31.

For this case, by adding the Integrated Damping System and taking advantage of the benefits of damping, it is possible to control the accelerations in the tower. This is usually the main reason which leads to the inclusion of a TMD or adding supplementary damping to a tower. Yet, as the Integrated Damping System is a redundant system, following the procedure in [76], it is possible to reduce the applied mean wind-induced load by $14 \%$ for the case of small displacement (1.9\% additional equivalent damping), and by $23 \%$ for the case of large displacement (55\% additional equivalent damping). This reduction in wind loads can lead to substantial savings in the superstructure and in the foundations. The dynamically-induced wind loads will depend on each specific case, but it can be concluded that by accounting for the Integrated Damping System the loading induced in the tower can be considerably reduced enabling optimization of building design. Moreover, as shown before, by implementing an Integrated Damping System, the response of the tower for the 7 considered seismic excitations can be reduced by up to $67 \%$, with an average of $47 \%$ and $15 \%$ for the small and large displacement cases, respectively.

\section{Concluding Remarks}

A new damping system referred to as the 'Integrated Damping System (IDS)' has been proposed and investigated in this paper. It originates from the idea of using part of the own mass of the building as the damper mass of a conventional tuned mass damper. By enabling two parts of the building to move differentially, it is possible to mobilize a considerably larger mass and thus dissipate a significantly larger amount of energy than is practically possible with an added mass of a tuned mass damper. The proposed system makes uses of the fact that due to the large mobilized mass, only a relatively small differential movement is required to provide large damping values. Moreover, as users do not typically perceive building 
movements, but rather only the accelerations, by using Fluid Viscous Dampers it is possible to control the accelerations, and thus enable part of the building to act as the damper mass.

The proposed Integrated Damping System results in a non-classically damped structure, which has the merit of providing damping by enabling two parts of the building to move differentially so that the overall stiffness of the building is maintained. This contrasts with conventional damping systems which typically reduce the overall stiffness of the building in order to provide damping by the increased deformation levels. This becomes a major benefit when applied to tall buildings as it implies that the system can be applied to tall buildings with no specific height limitation.

In addition to the above, and in contrast to a conventional TMD, the proposed system does not rely on one specific mechanism that could become non-operational due to, for example, maintenance. Since two parts of the building are connected with several FVDs, it is possible to consider it as a highly redundant damping arrangement. Moreover, the additional damping is not only used to reduce the level of accelerations of a tall building from a serviceability point of view, but it can also be used to greatly reduce both the seismic and wind responses. This can lead to a considerable mitigation of the level of forces that a tall building could experience, and thus a significant reduction in the overall size of the structural elements.

As Fluid Viscous Dampers cannot resist any static loads, to ensure the lateral stability of the damper mass as well as to resist the static wind load and control the degree of differential movement, the Integrated Damping System uses springs acting in parallel with the FVD such that the degree of differential movement between the two parts is controlled by the stiffness of the springs. The amount of additional equivalent damping that the system provides is thus directly related to the stiffness of the spring, as this determines the amount of differential movement that is enabled between its two ends.

As described in this paper, to assess the amount of additional equivalent damping that the IDS could provide in a typical design situation, its performance was examined for an illustrative $250 \mathrm{~m}$ tall building, although it should be noted that additional investigations would be required prior to the implementation of the system in a specific practical application. By taking advantage of the design decision of locating the communication cores outside of the main plan area of the building, it was possible to allow the differential movement of a large portion of the floor with respect to the cores. Additionally, in order to offer a more realistic and optimized application, the system was only implemented in the top block of the five office 
volumes that formed the tower. A parametric assessment was consequently performed to determine the amount of additional damping that could be obtained depending on the stiffness of the springs. Two spring stiffness boundary cases, within practical ranges, were adopted and investigated: a relatively stiff one and a relatively flexible one.

For the stiff springs, which enabled only a maximum differential movement of $25 \mathrm{~mm}$ under typical code-imposed static wind loading, it was possible to obtain a $1.9 \%$ additional equivalent damping. Besides controlling serviceability accelerations, this additional damping resulted in a $14 \%$ reduction in the static code wind load and a maximum reduction of $30 \%$ in the top displacement of the tower, with an average reduction of $19 \%$ under seven selected seismic excitations. For the soft spring case, which enabled a $250 \mathrm{~mm}$ differential movement under the code wind load, the value of the additional equivalent damping was increased to $55 \%$ of the critical. This led to a $23 \%$ reduction in the code static wind load and a maximum reduction in the top displacement of the building for the seven seismic excitations of up to $67 \%$.

From the results of the parametric investigation, it was possible to ascertain the considerable performance benefits that the proposed Integrated Damping System can provide especially in a tall building. By providing additional supplementary damping, a high level of stiffness and strength optimization can be employed in the design, leading to significant economic savings, both in the superstructure and the foundations. This not only leads to a reduction in the sizes of the primary and secondary structural elements but also enables more flexible and taller buildings to be conceived. 


\section{Figures}

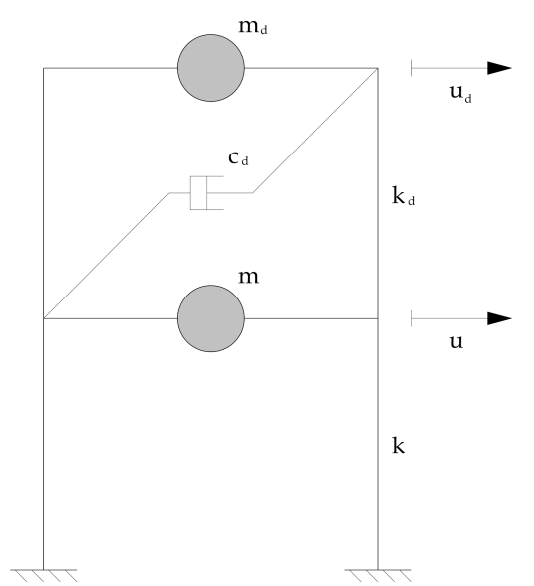

Figure 1: Simplified 2DOF system of SDOF with an attached TMD

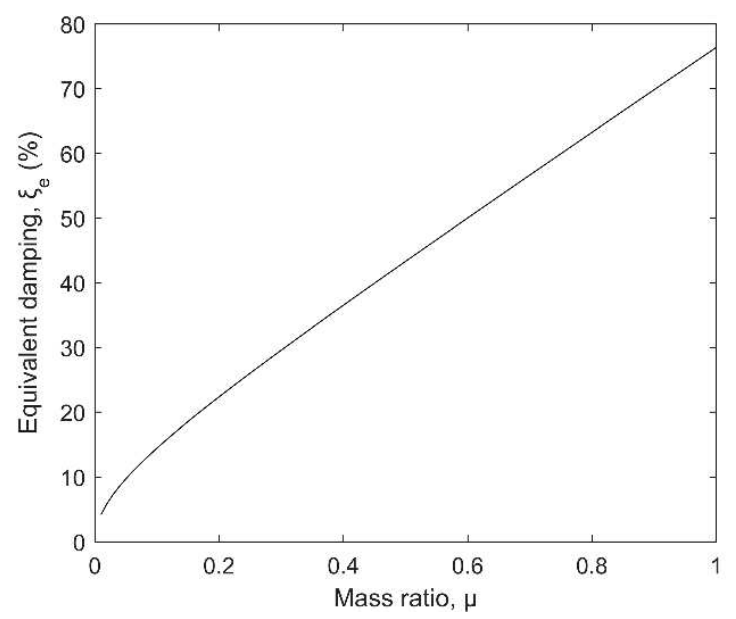

Figure 2: Equivalent damping under harmonic excitation

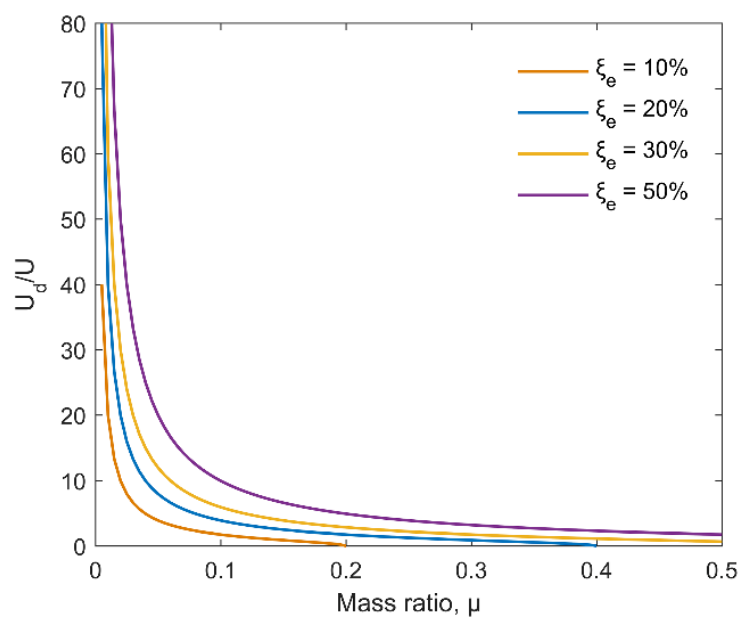

Figure 3: Variation in the ratio of maximum displacement amplitudes with respect to mass ratio for a target equivalent damping 


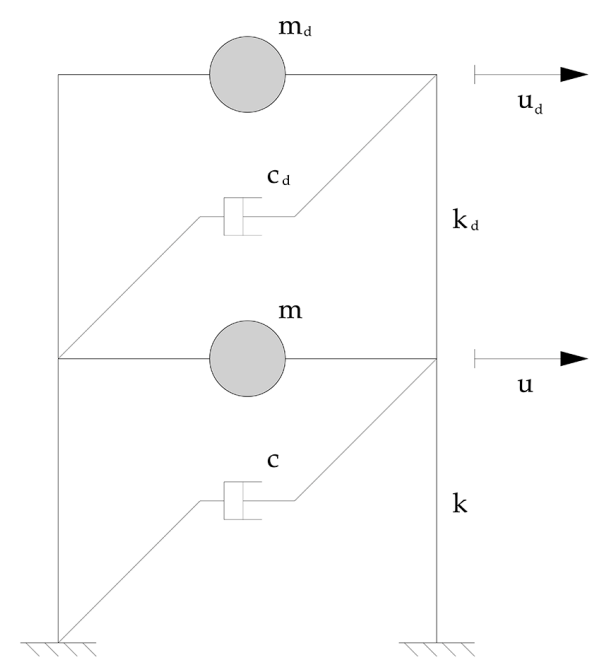

Figure 4: Continuously damped structure
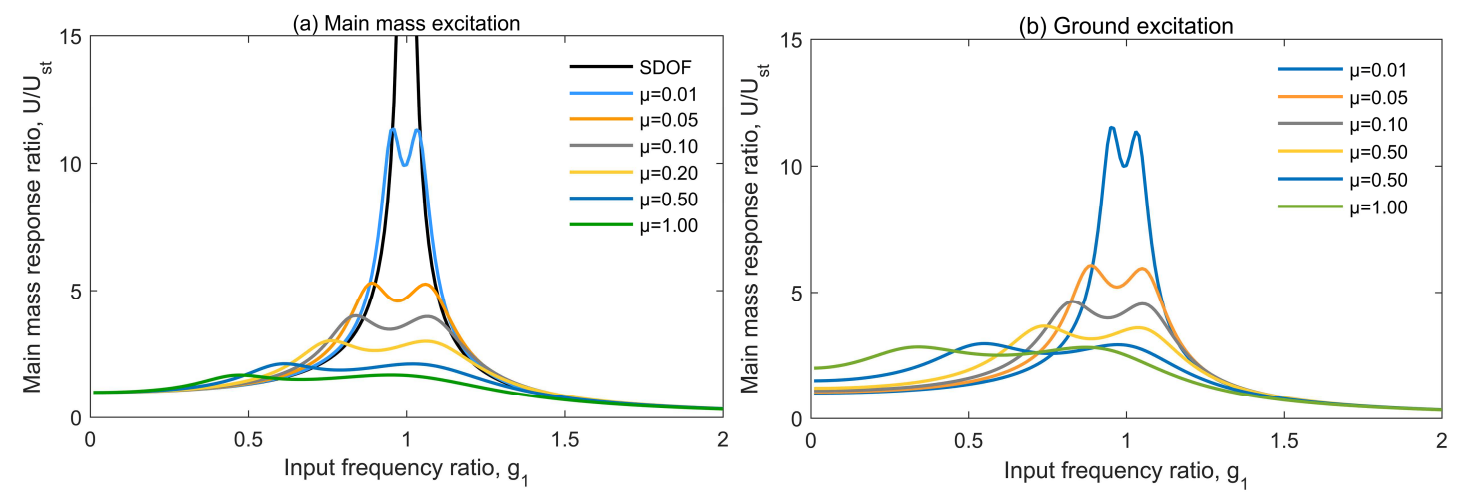

Figure 5: Dimensionless response of the system with different mass ratios under harmonic main mass excitation (a) and under harmonic ground excitation (b)
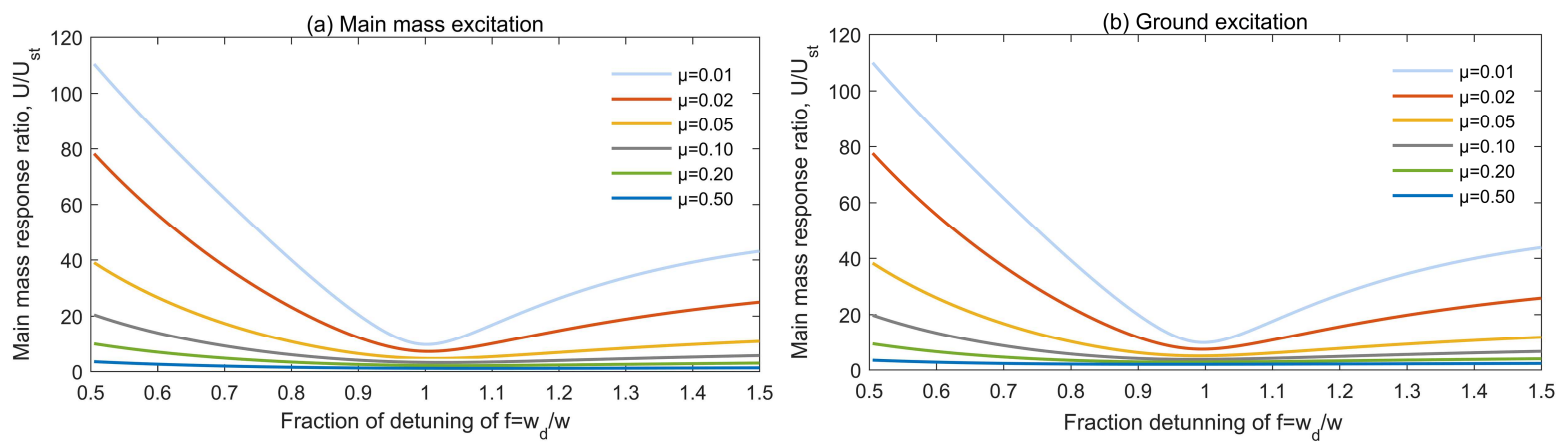

Figure 6: Effect of detuning in the system frequency under harmonic main mass excitation (a) and ground excitation (b) 

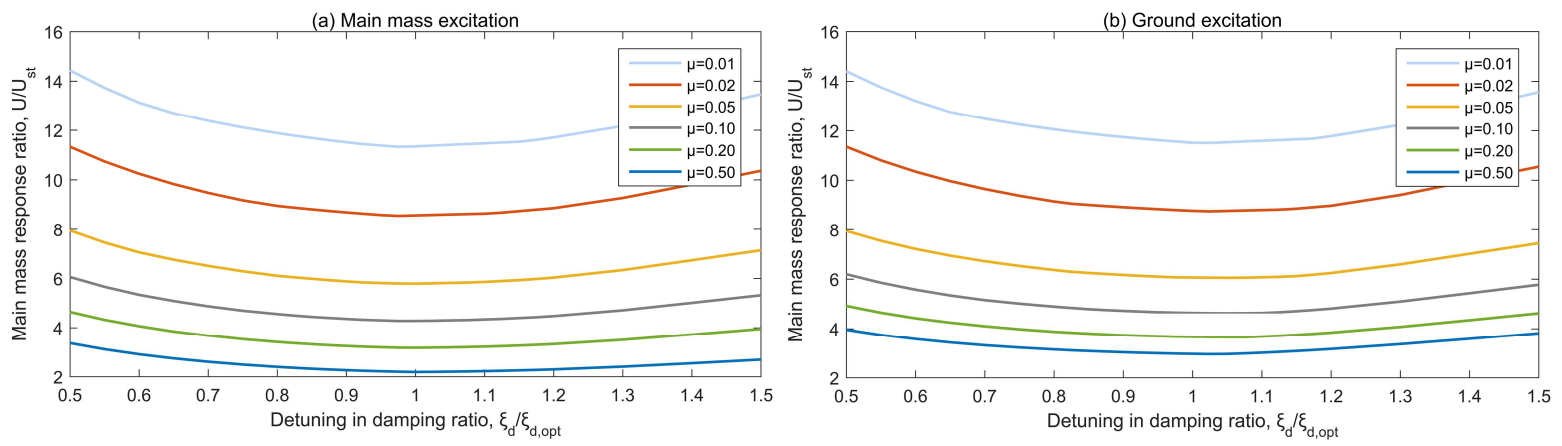

Figure 7: Effect of detuning in the damping ratio of the TMD mass under harmonic main mass excitation (a) and ground excitation (b)

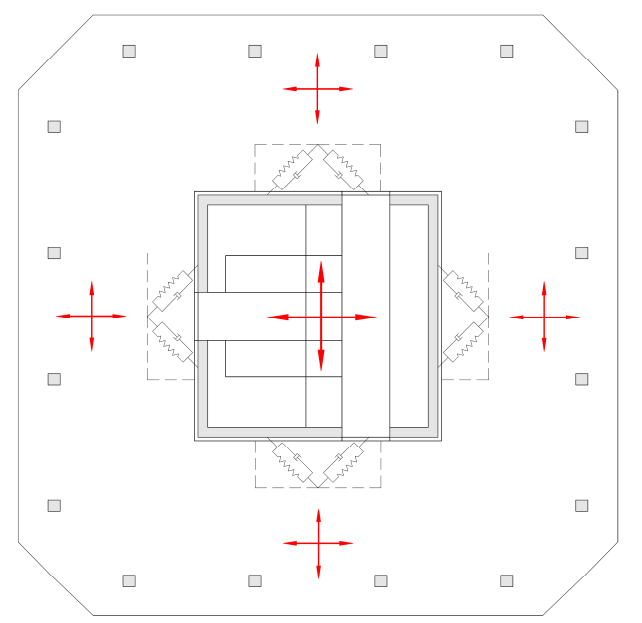

Figure 8: Integrated Damping System floor plan scheme 


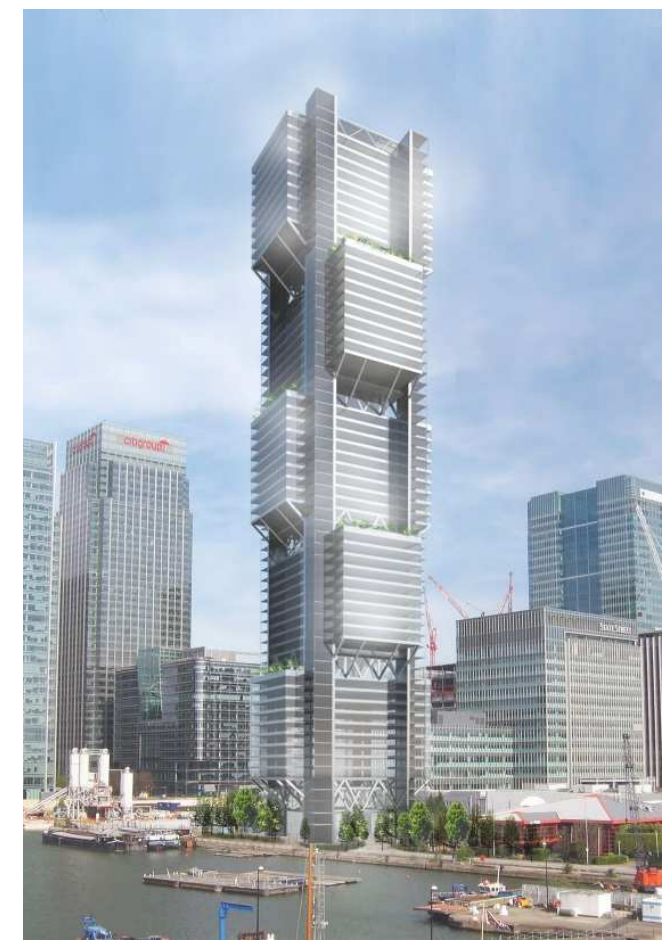

Figure 9: Tower visualization

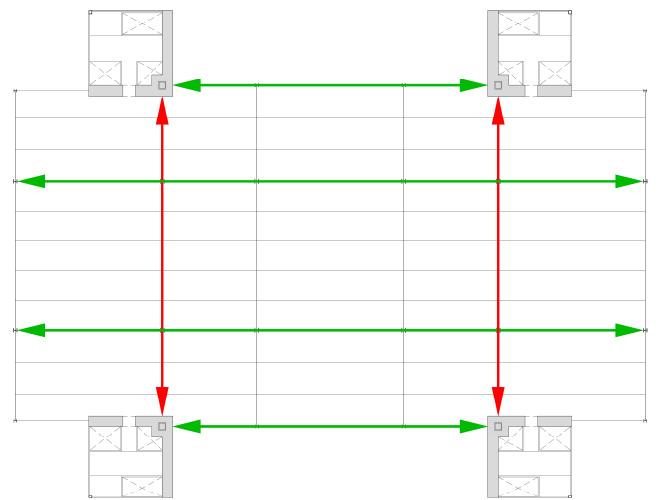

Figure 10: Primary (red) and secondary (green) trusses 

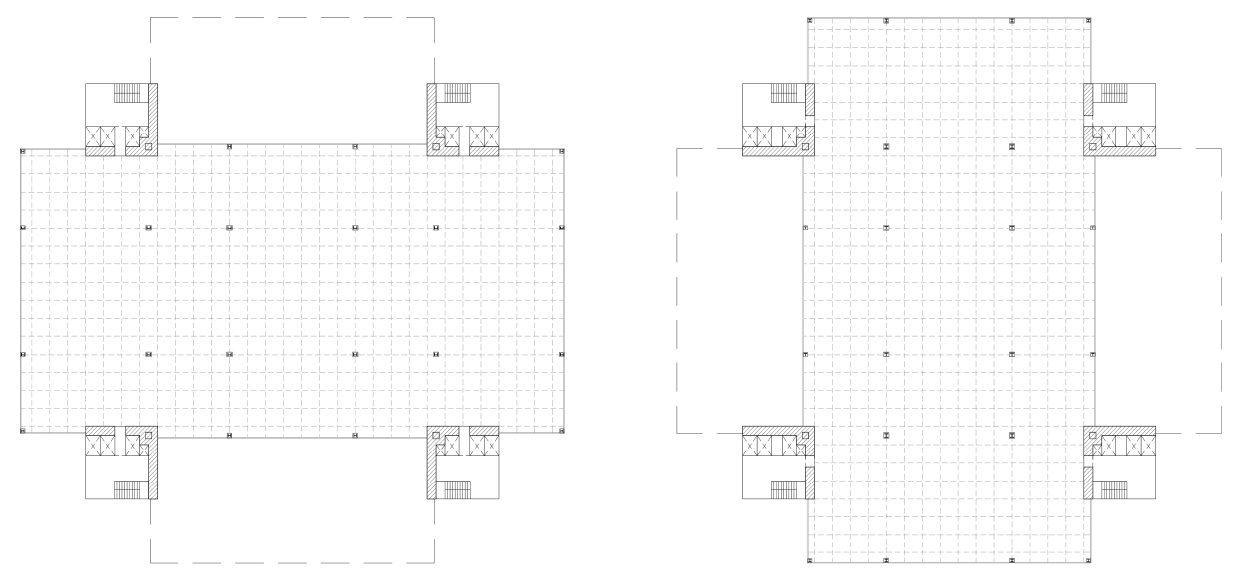

Figure 11: Typical office floors, Blocks 1, 3 and 5 (left), and blocks 2 and 4 (right)
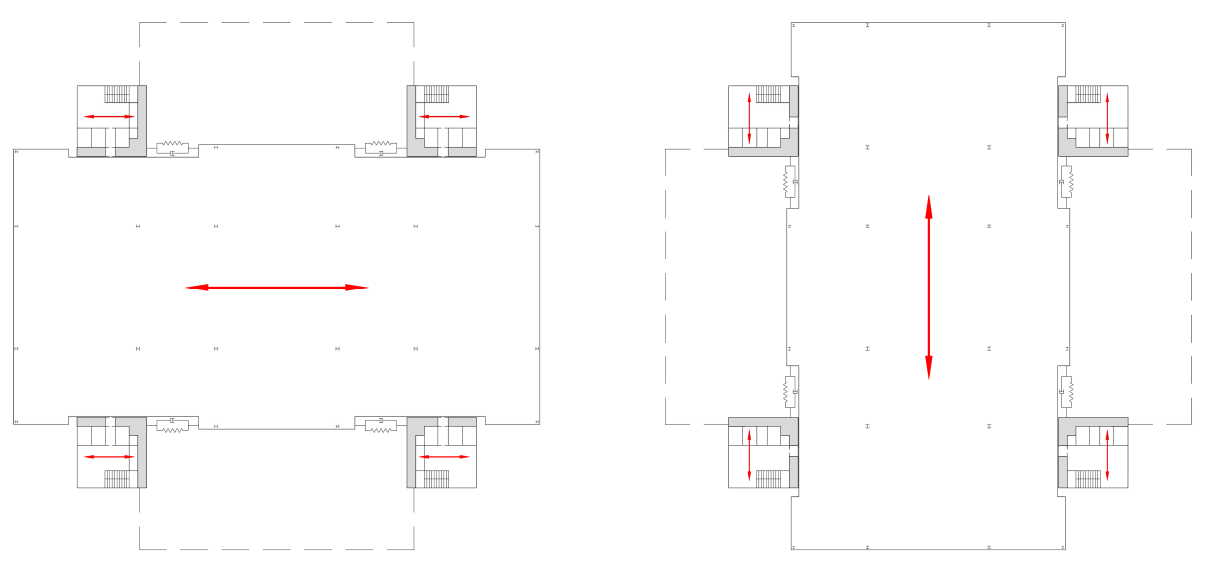

Figure 12: Integrated Damping System floor plan scheme 


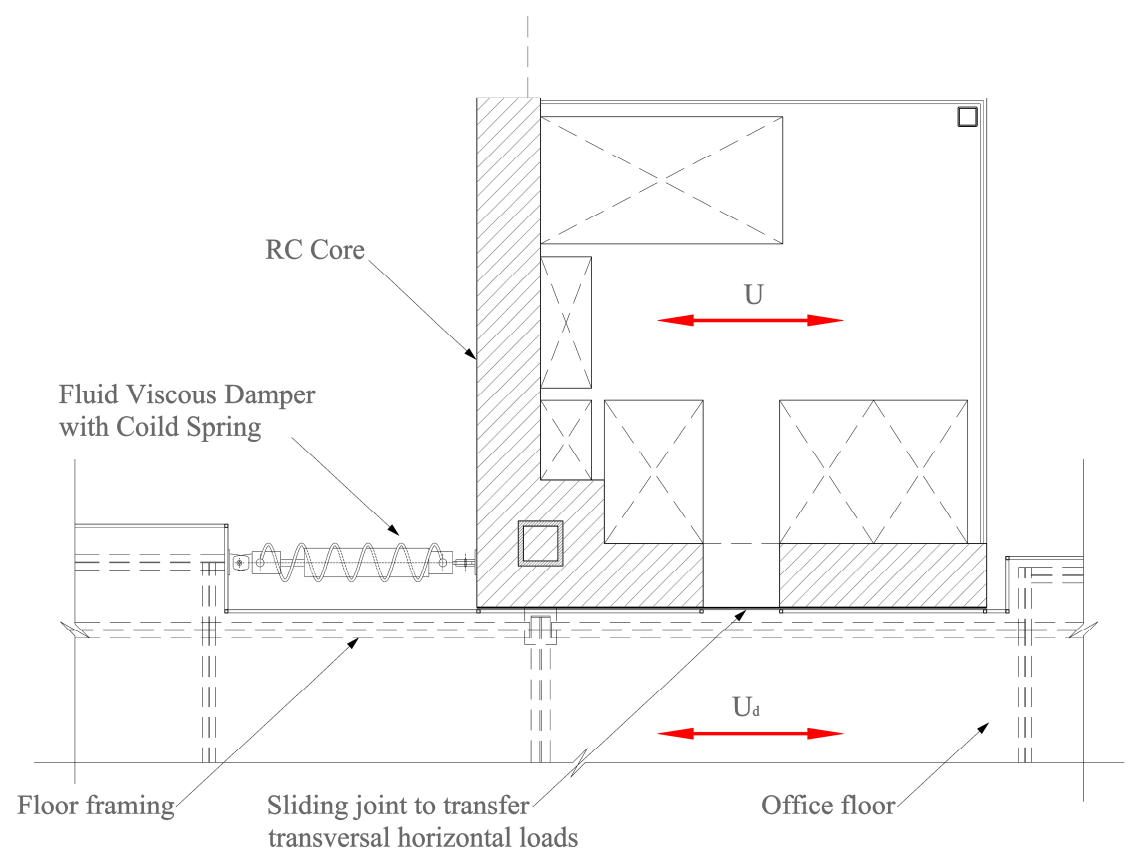

Figure 13: Close view of communication core-office floor plate interface

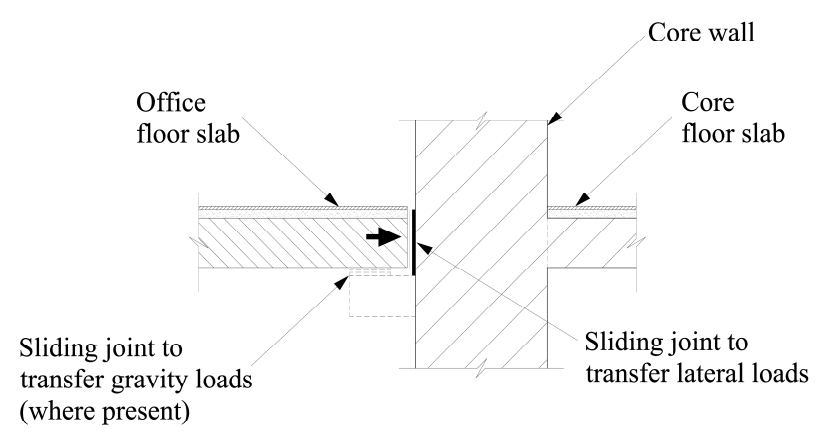

Figure 14: Cross-section at office floor-communication core interface showing movement and sliding joints 


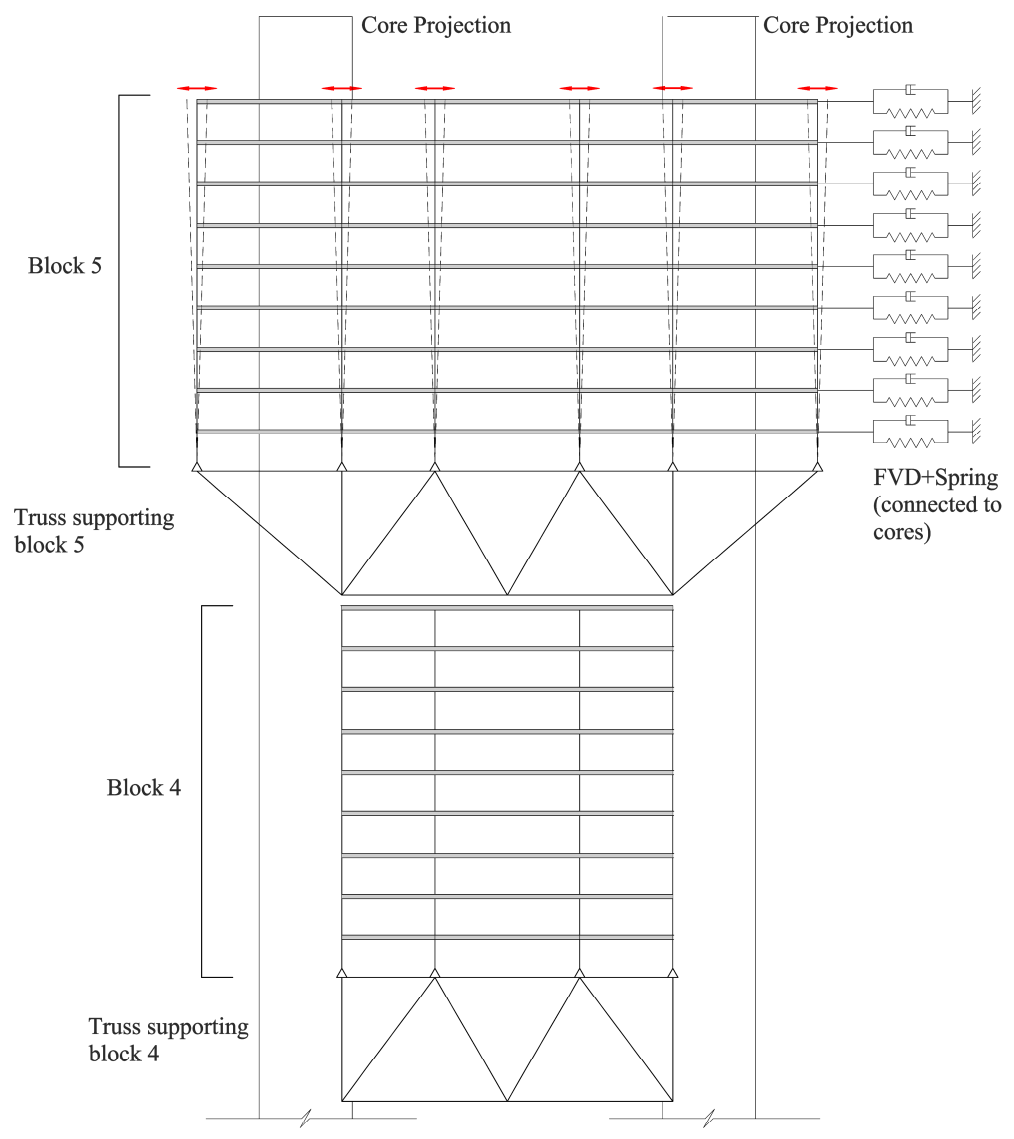

Figure 15: Schematic elevation of the top of the tower (top office block with the IDS system) 


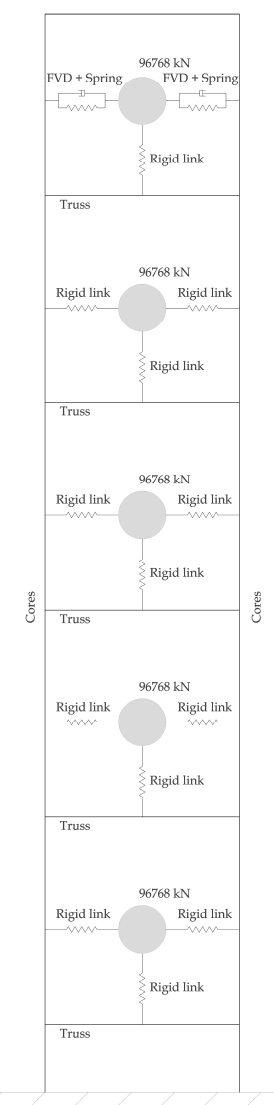

Figure 16: Simplified model of the tower

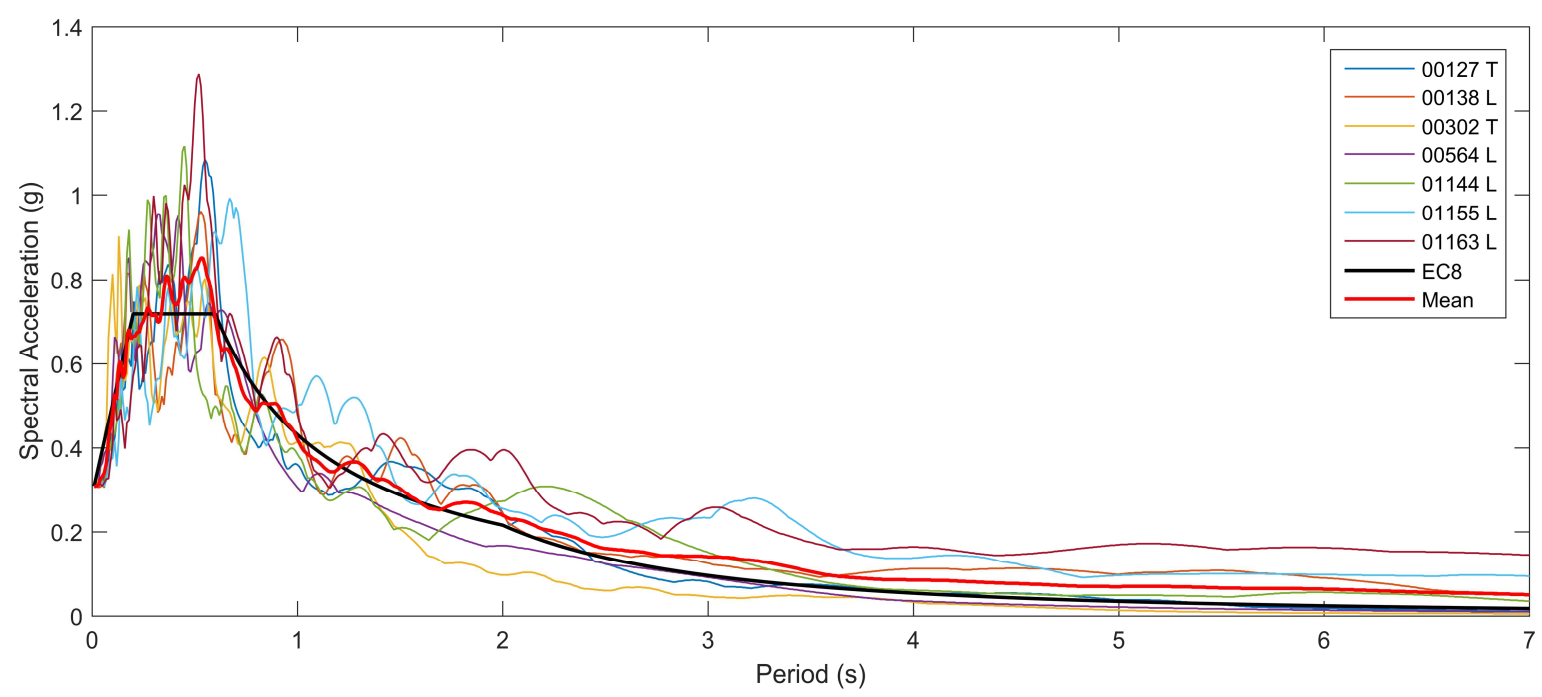

Figure 17: Scaled Response Spectrum of the seven selected earthquake records 

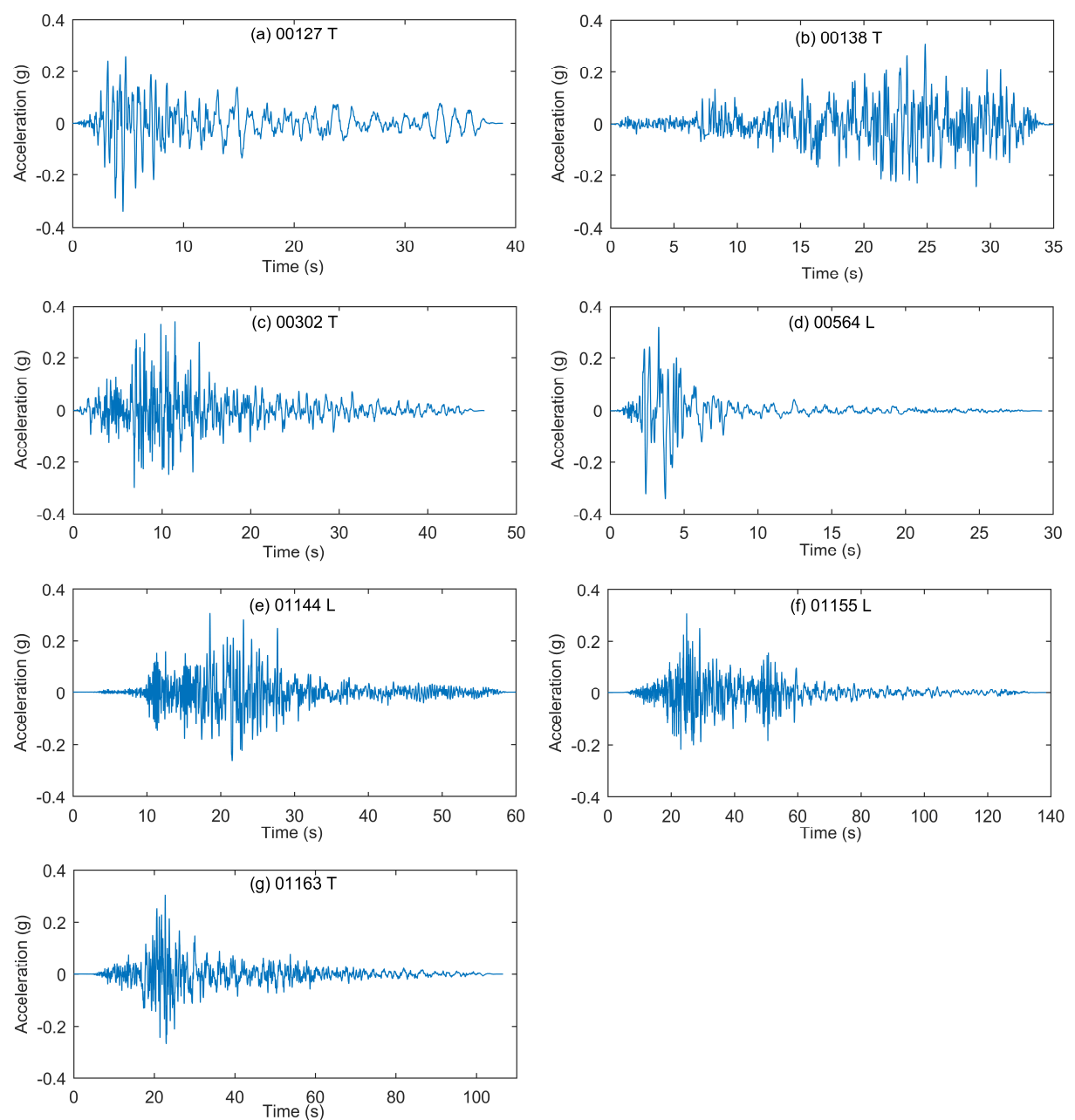

Figure 18: Scaled acceleration histories for the seven selected records (a-g)

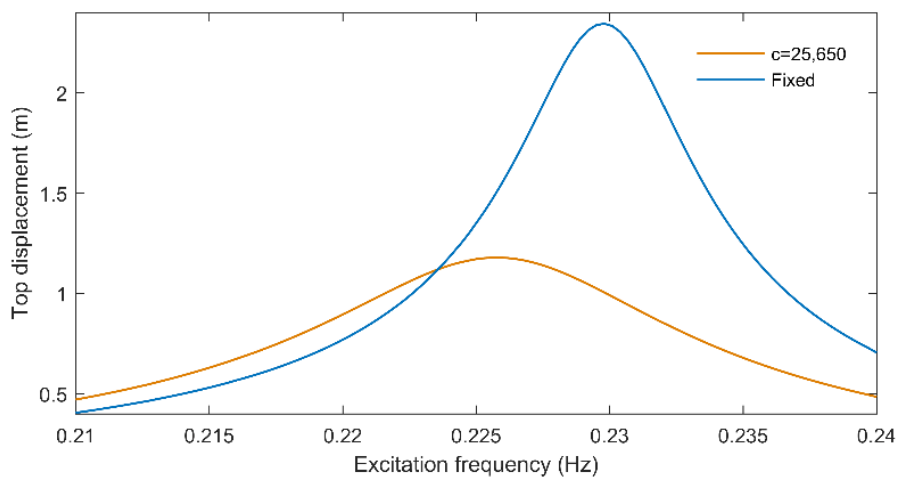

Figure 19: Peak response under a sweep excitation for a maximum differential displacement of $25 \mathrm{~mm}$ 


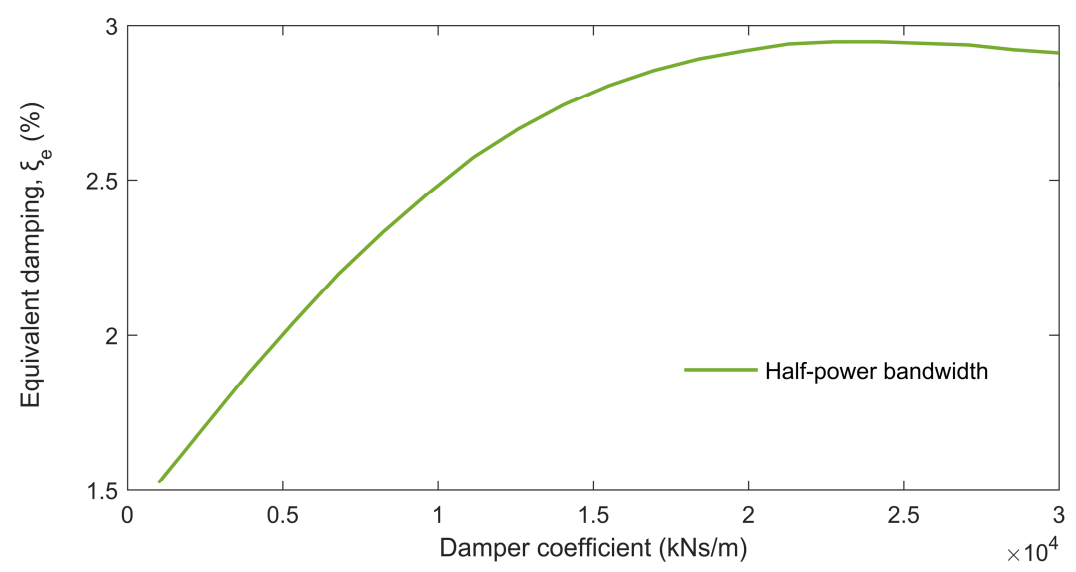

Figure 20: Equivalent damping versus damper coefficient for a spring stiffness allowing a maximum displacement of $25 \mathrm{~mm}$ under the design mean wind load

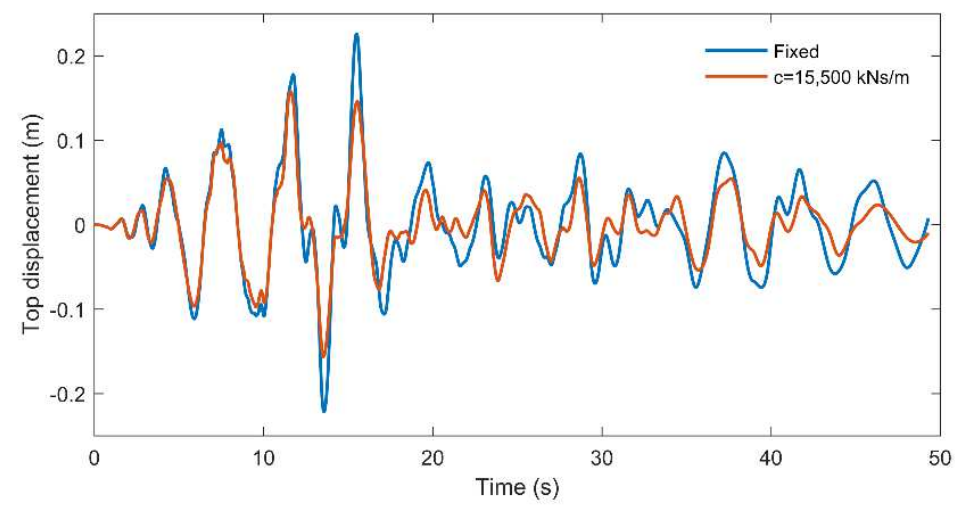

Figure 21: Displacement time history of the tower against the (c) $00330 \mathrm{~T}$ acceleration record for the small displacement case 


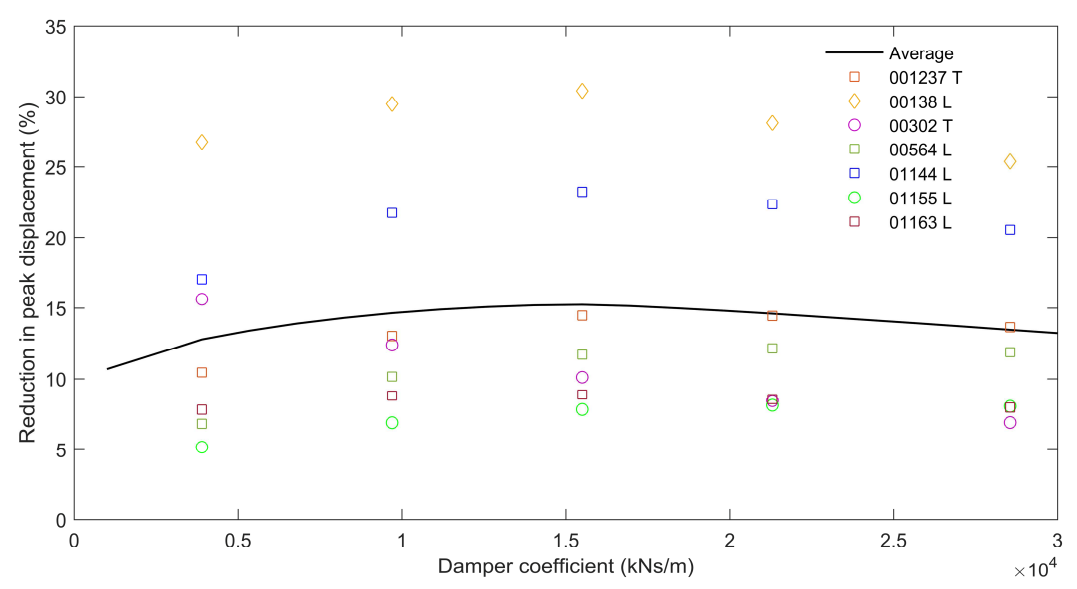

Figure 22: Reduction in the top displacement versus damper coefficient values for the 7 considered earthquake records, for a maximum differential displacement of $25 \mathrm{~mm}$

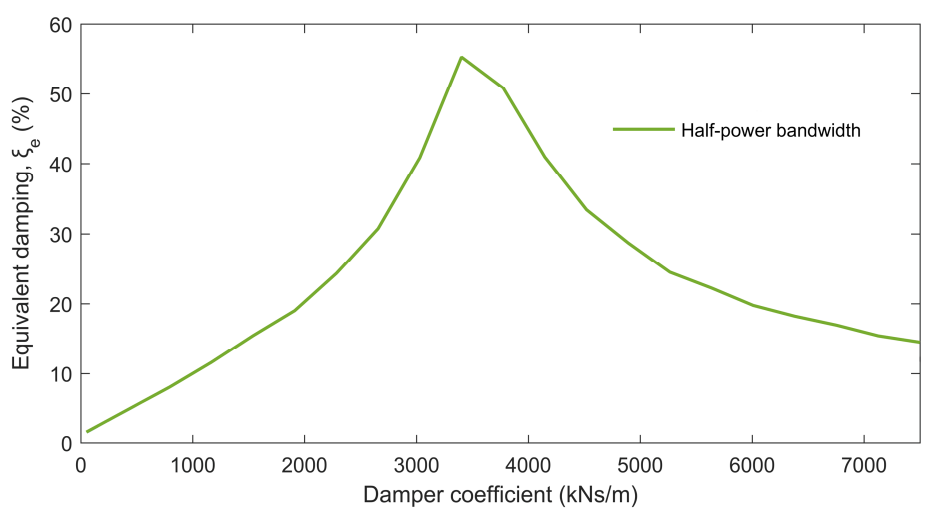

Figure 23: Equivalent damping versus damper coefficient for a spring stiffness allowing a maximum displacement of $250 \mathrm{~mm}$ under the design mean wind load

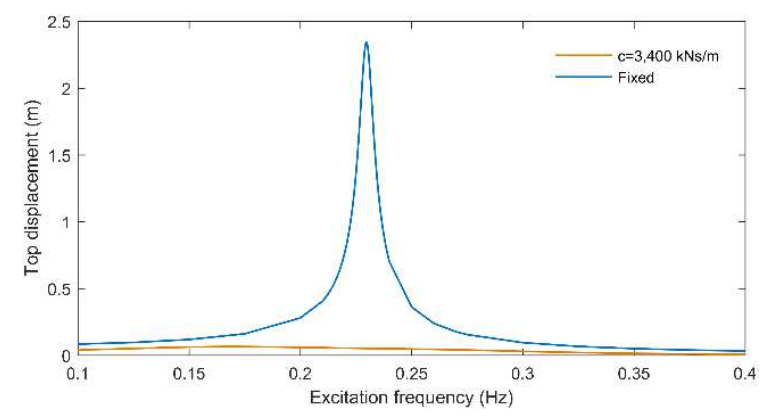

Figure 24: Peak response under a sweep excitation for a maximum differential displacement of $250 \mathrm{~mm}$ 


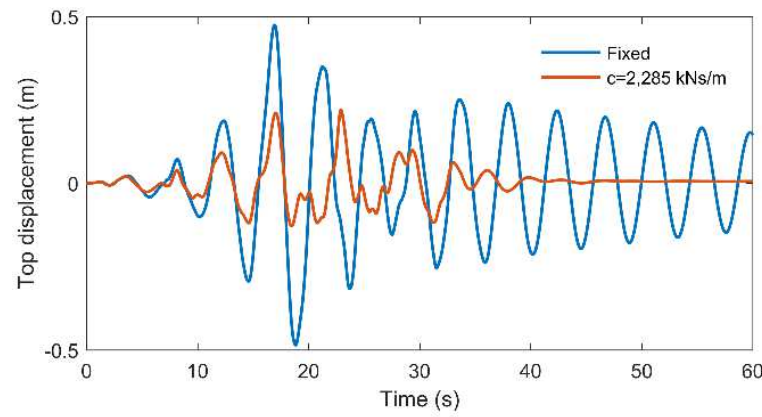

Figure 25: Displacement time history of the tower against the (b) $00138 \mathrm{~L}$ acceleration record for the large displacement case

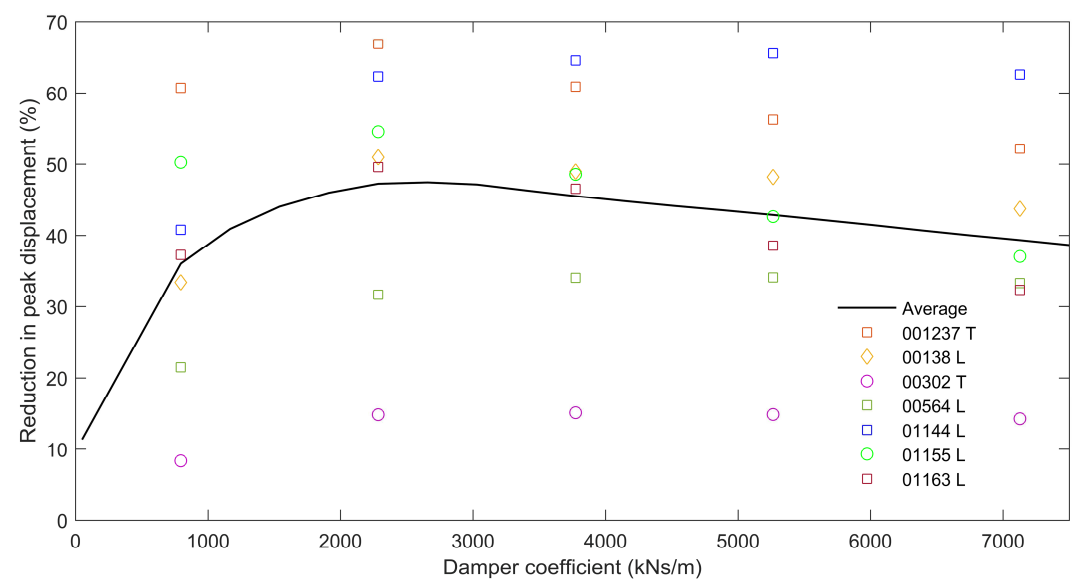

Figure 26: Reduction in the top displacement versus damper coefficient values for the 7 considered earthquake records, for a maximum differential displacement of $250 \mathrm{~mm}$.

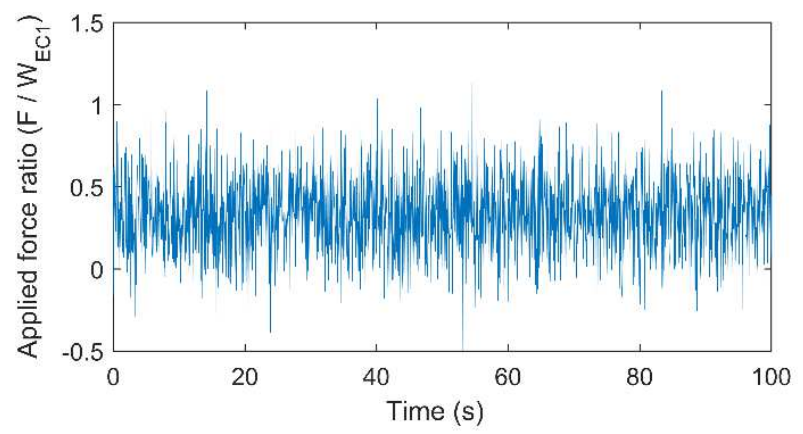

Figure 27: White noise function 


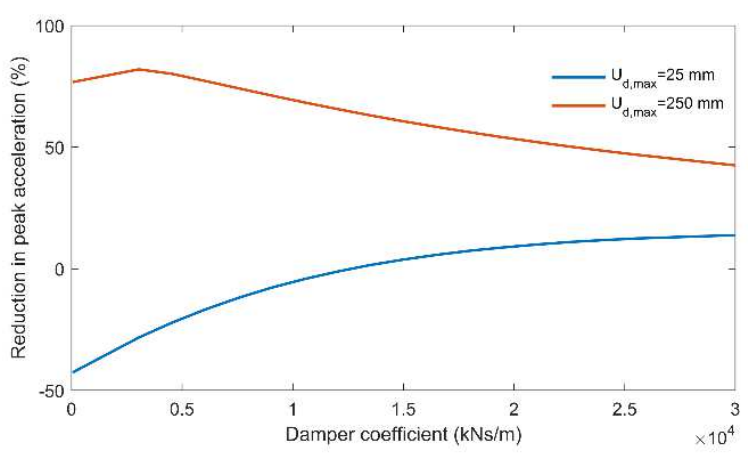

Figure 28: Reduction in peak acceleration under sinusoidal excitations versus the damper coefficient

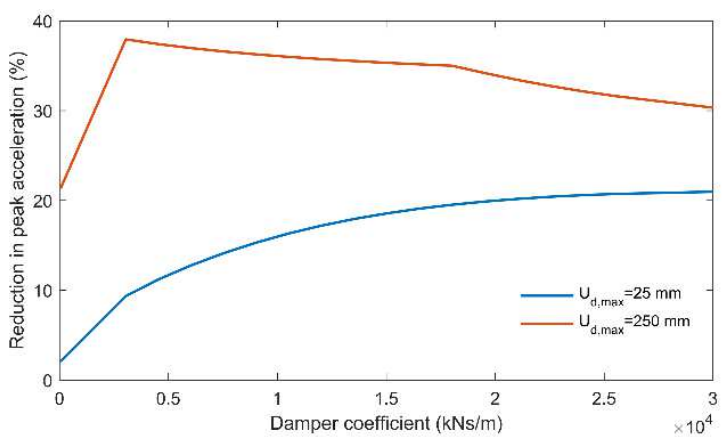

Figure 29: Reduction in peak acceleration under white noise excitation versus the damper coefficient

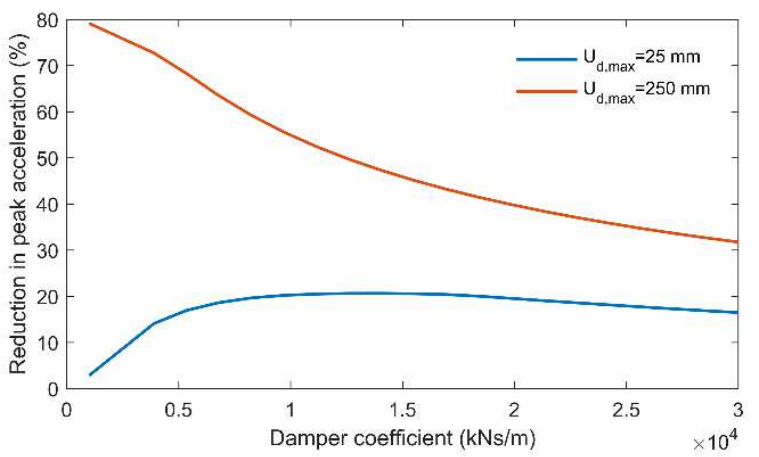

Figure 30: Average reduction in peak absolute acceleration for the seven selected records versus the damper coefficient 


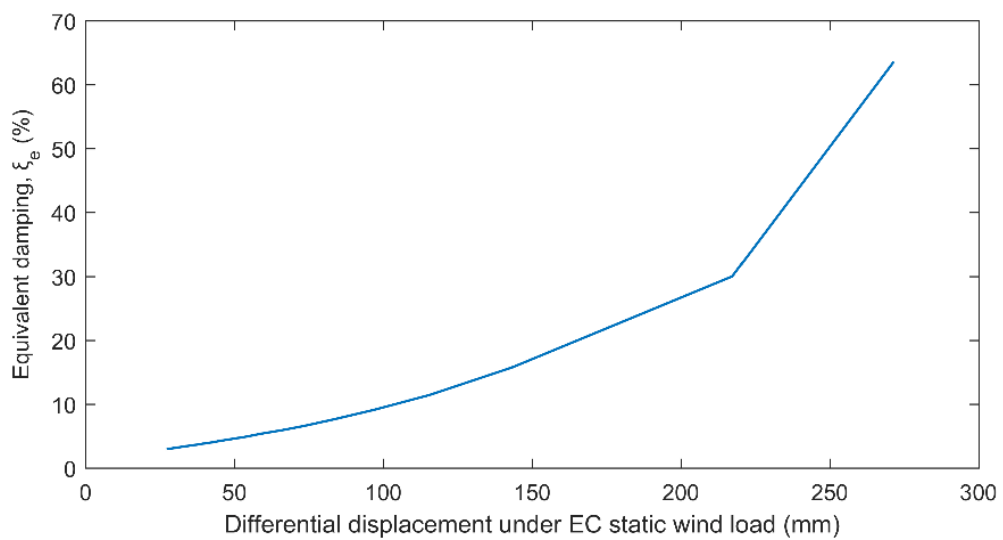

Figure 31: Relationship between the maximum differential displacement and the additional equivalent damping

\section{Tables}

\begin{tabular}{|c|c|c|c|c|c|c|c|c|}
\hline $\begin{array}{c}\text { NGA } \\
\text { Record No. }\end{array}$ & Earthquake Name & Date & $\begin{array}{c}\text { Magnitud } \\
\mathbf{e}\end{array}$ & $\begin{array}{c}\text { Distance to } \\
\text { Fault } \mathbf{( k m})\end{array}$ & $\begin{array}{c}\mathbf{V}_{\text {s30 }} \\
\mathbf{( m / s}\end{array}$ & $\begin{array}{c}\text { PGA } \\
\mathbf{( g )}\end{array}$ & $\begin{array}{c}\text { Scale } \\
\text { Factor }\end{array}$ & D $_{\text {RMS }}$ \\
\hline $\mathbf{0 0 1 2 7} \mathbf{T}$ & Friuli, Italy & $1976-09-11$ & 5.5 & 15.1 & 339 & 0.04 & 7.55 & 0.05 \\
\hline $\mathbf{0 0 1 3 8} \mathbf{L}$ & Tabas, Iran & $1978-09-16$ & 7.4 & 24.1 & 339 & 0.11 & 2.89 & 0.07 \\
\hline $\mathbf{0 0 3 0 2} \mathbf{~ T}$ & Irpinia, Italy & $1980-11-23$ & 6.2 & 22.7 & 339 & 0.10 & 3.19 & 0.06 \\
\hline $\mathbf{0 0 5 6 4} \mathbf{L}$ & Kalamata, Greece & $1986-09-13$ & 6.2 & 11.2 & 339 & 0.25 & 1.24 & 0.05 \\
\hline $\mathbf{0 1 1 4 4} \mathbf{L}$ & Gulf of Aqaba & $1995-11-22$ & 7.2 & 43.3 & 355 & 0.10 & 3.18 & 0.07 \\
\hline $\mathbf{0 1 1 5 5 L}$ & Kocaeli, Turkey & $1999-08-17$ & 7.5 & 60.45 & 275 & 0.10 & 2.97 & 0.10 \\
\hline $\mathbf{0 1 1 6 3 L}$ & Kocaeli, Turkey & $1999-08-17$ & 7.5 & 58.3 & 425 & 0.09 & 3.41 & 0.13 \\
\hline
\end{tabular}

Table 1: Seismological and scaling data for the seven selected records 


\section{References}

[1] Longarini, N., Cabras, L., Zucca, M., Chapain, S., Aly, A.M. Structural Improvements for Tall Buildings under Wind Loads: Comparative Study. Shock and Vibration 2017, 2031248. doi: $10.1155 / 2017 / 2031248$.

[2] Den Hartog, J. P. Mechanical vibrations. 34 ${ }^{\text {th }}$ ed, McGraw-Hill, New York 1956.

[3] Ormondroyd, J. \& Den Hartog, J. P. The theory of dynamic vibration absorber. Trans. ASME 1928. APM-50-7, 9-22.

[4] Gutierrez Soto, M. \& Adeli, H. Tuned Mass Dampers. Arch. Comput Methods Eng 2013. 20: 419-431. doi:10.1007/s11831-013-9091-7

[5] Kwok, K. C. S. \& Samali, B. Performance of tuned mass dampers under wind loads. Engineering Structures 1995. Elsevier Science LTd. Great Britain. Vol. 17, No. 9 pp. 655-667. doi:10.1016/0141-0296(95)00035-6.

[6] Warburton, G.B. \& Ayorinde, E.O. Optimum absorber parameters for simple systems. Earthquake Engineering and Structural Dynamics 1980, 8, pp 197-217. DOI:10.1002/ eqe.4290080302.

[7] Warburton, G.B. Optimum Absorber Parameters for various combinations of response and excitation parameters. Earthquake Engineering and Structural Dynamics 1982, 10, pp 381401. doi:10.1002/eqe.4290100304.

[8] Rana, R. \& Soong, T. T. Parametric study and simplified design of tuned mass dampers. Engineering Structures 1998. Elsevier Science LTd. Great Britain. Vol. 20, No. 3 pp 193-204. doi:10.1016/s0141-0296(97)00078-3.

[9] Chang, C. C. Mass dampers and their optimal designs for building vibration control. Engineering Structures 1999. Elsevier Science LTd. Great Britain. Vol. 21, pp 454-463. doi:10.1016/s0141-0296(97)00213-7.

[10] Lee, C., Chen, Y., Chung, L \& Wang, Y. Optimal design theories and applications of tuned mass dampers. Engineering Structures 2006 Elsevier Science LTd. Great Britain. Vol 28, pp 43-53. doi:10.1016/j.engstruct.2005.06.023.

[11] Gutierrez Soto, M. \& Adeli, H. Optimum parameters of tuned mass dampers for vibration control of irregular highrise building structures. Journal of Civil Engineering and Management 2014, 20(5), pp 609-620. doi:10.3846/13923730.2014.967287

[12] Sadek, F., Mohraz, B., Taylor, A.W. \& Chung, R. M. A method of estimating the parameters of tuned mass dampers for seismic applications. Earthquake Engineering and Structural Dynamics 1998, 26 (6), pp 617-635. doi: 10.1002/(SICI)10969845(199706)26:6<617::AID-EQE664>3.0.CO;2-Z 
[13] Etedali, S \& Mollayi, N. Cuckoo Search-Based Least Squares Support Vector Machine Models for Optimum Tuning of Tuned Mass Dampers. International Journal of Structural Stability and Dynamics 2018, 19, n 02. Doi: 10.1142/S0219455418500281

[14] Leung, A.Y.T., Zhang, H., Cheng, C. C. \& Lee, Y.Y. Particle swarm optimization of TMD by non-stationary base excitation during earthquake. Earthquake Engineering and Structural Dynamics 2008, 37, pp 1223-1246. doi: 10.1002/eqe.811

[15] Keshtegar, B. \& Etedali, S. Nonlinear mathematical modelling and optimum design of tuned mass dampers using adaptive dynamic harmony search algorithm. Struct. Control Health Monit. 2018, 25:e2163. doi: 10.1002/stc.2163

[16] Salvi, J. \& Rizzi, E. Optimum tuning of tuned mass dampers for frame structures under earthquake excitation. Struct. Control Health Monit. 2015, 22, pp-707-725. Doi: $10.1002 /$ stc. 1710

[17] Yamaguchi, H. \& Harnpornchai, N. Fundamental characteristics of multiple tuned mass dampers for suppressing harmonically forced oscillations. Earthquake Engineering and Structural Dynamics 1993, 22, pp 51-62. doi:10.1002/eqe.4290220105.

[18] Matta, E. \& De Stefano, A. Seismic performance of pendulum and translational roofgarden TMDs. Mechanical Systems and Signal Processing 2009. 23, 908-921. doi:10.1016/j.ymssp.2008.07.007

[19] Feng, M. \& Mita, A. Vibration Control of Tall Buildings Using Mega SubConfiguration. Journal of Engineering Mechanics, ASCE 1995; 121;1082-1088. doi: 10.1061/(ASCE)07339399(1995) 121:10(1082)

[20] Chey, M., Chase, J., Mander, J. \& Carr, A. Semic-active tuned mass damper building systems: Design. Earthquake Engineering and Structural Dynamics 2010; 39, pp 119-139. doi: 10.1002/eqe. 934

[21] Angelis, M., Perno, S. \& Reggio, A. Dynamic response and optimal design of structures with large mass ratio TMD. Earthquake Engineering and Structural Dynamics 2012; 41, pp 4160. doi: 10.1002/eqe.1117

[22] Xiang, P. \& Nishitani A. Seismic vibration control of building structures with multiple tuned mass damper floors integrated. Earthquake Engineering and Structural Dynamics 2014; 43, pp 909-925. doi: 10.1002/eqe.2379

[23] Mahmoud, H. \& Chulahwat, A. Response of building systems with suspended floor slabs under dynamic excitations. Engineering Structures 2015, 104, 155-173. doi:10.1016/j.engstruct.2015.09.027. 
[24] Nielsen, E. J., Lai, M., Soong, T. T. \& Kelly, J. M. Viscoelastic damper overview for seismic and wind applications. Smart Structures and Materials 1996: Passive Damping and Isolation. Feb 26 - 27 96, San Diego, CA, United states, Society of Photo-Optical Instrumentation Engineers. pp.138-144. doi:10.1117/12.239081.

[25] Samali, B. \& Kwok, K. C. S. Use of viscoelastic dampers in reducing wind- and earthquake-induced motion of building structures. Engineering Structures 1995. 17 (9), 639654. doi:10.1016/0141-0296(95)00034-5.

[26] Constantinou, M. \& Symans, M. Experimental and Analytical Investigation of Seismic Response of Structures with Supplemental Fluid Viscous Dampers. National Center for Earthquake Engineering Research 1992. Buffalo, NY. Report number: Technical Report NCEER- 92-0032.

[27] Taylor, D. Mega Brace Seismic Dampers for the Torre Mayor Project at Mexico City. Taylor Devices Technical Report 2003. www.taylordevices.com [10 July 2016]

[28] Constantinou, M. C., Tsopelas, P., Hammel, W. \& Sigaher, A. N. Toggle-brace-damper seismic energy dissipations systems. Journal of Structural Engineering 2001. New York, N. Y. 127 (2), 105-112. doi:10.1061/(asce)0733-9445(2001)127:2(105).

[29] McNamara, R. J. \& Taylor, D. P. Fluid viscous dampers for high-rise buildings. Structural Design of Tall and Special Buildings 2003. 12 (2), 145-154. doi:10.1002/tal.218.

[30] Sigaher, A. N. \& Constantinou, M.C. Scissor-Jack-Damper Energy Dissipation System. Earthquake Spectra 2003. 19 (1), 133-158. doi:10.1193/1.1540999.

[31] Chapain, S. \& Aly, A.M. Vibration Attenuation in High-Rise Buildings to Achieve SystemLevel Performance under Multiple Hazards. Engineering Structures 2019, 197(15), 109352. doi: 10.1016/j.engstruct.2019.109352.

[32] Gutierrez Soto, M. \& Adeli, H. Placement of control devices for passive, semi-active, and active vibration control of structures. Scientia Iranica 2013. Vol 20(6), pp 1567-1578.

[33] Smith, R. J. \& Willford, M. R. The damped outrigger concept for tall buildings. Structural Design of Tall and Special Buildings 2007. 16 (4), 501-517. doi:10.1002/tal.413.

[34] Willford, M. R. \& Smith, R. J. Performance based seismic and wind engineering for 60 story twin towers in Manila. The 14th World Conference on Earthquake Engineering 2008, Beijing, China.

[35] Infanti, S., Robinson, J. \& Smith, R. Viscous dampers for high-rise buildings. The $14^{\text {th }}$ World Conference on Earthquake Engineering 2008. Beijing, China. 
[36] Jackson, M. \& Scott, D.M. Increasing efficiency in tall buildings by damping. Structures Congress 2010, Orlando, FL, United States, American Society of Civil Engineers (ASCE). pp.3132-3142. doi:10.1061/41130(369)281.

[37] Smith, R. The Damped Outrigger - Design and Implementation. International Journal of High-Rise Building 2016. 5(1), 63. doi:10.21022/ijhrb.2016.5.1.63.

[38] He, X. \& Lu, Z. Seismic fragility assessment of a super tall building with hybrid control strategy using IDA method. Soil Dynamics and Earthquake Engineering 2019. Vol 123, pp 278-291. doi:10.1016/j.soildyn.2019.05.003

[39] Lu, Z., He, X. \& Zhou, Y. Performance-based seismic analysis on a super high-rise building with improved viscously damped outrigger system. Struct. Control Health Monit. 2018, 25:e2190. doi:10.1002/stc. 2190

[40] Smith, R., Merello, R. \& Willford, M. Intrinsic and supplementary damping in tall buildings. Proceedings of the Institution of Civil Engineers, Structures and Buildings 2010. 163111-18. doi:10.1680/stbu.2010.163.2.111.

[41] Randall, S.E., Halstead, D.M. \& Taylor, D.L. Optimum Vibration Absorbers for Linear Damped Systems. Journal of Mechanical Design 1981. 103 (4), pp 908-913. doi:10.1115/1.3255005.

[42] Connor, J. 4. Tuned Mass Dampers. Introduction to Structural Motion Control 2002. MIT-Prentice Hall, pp 217-285

[43] Kareem, A. \& Kline, S. Performance of Multiple Mass Dampers under Random Loading. Journal of Structural Engineering 1995. 121, 2, pp 348-361. doi:10.1061/(asce)07339445(1995)121:2(348).

[44] Wiesner, K.B. Tuned Mass Dampers to Reduce Building Wind Motion. ASCE Convention and Exposition 1979. Preprint 3510, Boston, April, 1979

[45] Nasr, A., Mrad, C. \& Nasri, R. Friction tuned mass damper optimization for structure under harmonic force excitation. Structural Engineering and Mechanics 2018. 65(6), pp 761769. doi: 10.12989/sem.2018.65.6.761.

[46] Etedali, S., Akbari, M., \& Seifi, M. MOCS-based optimum design of TMD and FTMD for tall buildings under near-field earthquakes including SSI effects. Soil Dynamics and Earthquake Engineering 2019, 119, pp 36-50. doi: 10.1016/j.soildyn.2018.12.027.

[47] Etedali, S., Seifi, M., \& Akbari, M. A numerical study on optimal FTMD parameters considering soil-structure interaction effects. Geomechanics and Engineering 2018, 16(5), pp 527-538. doi: 10.12989/GAE.2018.16.5.527. 
[48] Inaudi, J.A. \& Kelly, J.M. Mass Damper Using Friction-Dissipating Devices. Journal of Engineering Mechanics 1995. 1(121). doi: 10.1061/(ASCE)0733-9399(1995)121:1(142).

[49] Ricciardelli, F. \& Vickery, B.J. Tuned vibration absorbers with dry friction damping. Earthquake Engineering and Structural Dynamics 1999, 28: pp 707-723. doi: 10.1002/(SICI)1096-9845(199907)28:7<707::AID-EQE836>3.0.CO;2-C

[50] $\mathrm{Xu}, \mathrm{K}$. and Igusa, T. Dynamic characteristics of multiple substructures with closely spaced frequencies. Earthquake Engineering and Structural Dynamics 1992, 21, pp 1059-1070. doi:10.1002/eqe.4290211203.

[51] Aly, A.M. Proposed robust tuned mass damper for response mitigation in buildings exposed to multidirectional wind. Structural Design of Tall and Special Buildings 2015, 23(9), pp 664-691. doi: 10.1002/tal.1068.

[52] Aly, A.M. Control of wind-induced motion in high-rise buildings with hybrid TM/MR dampers. Wind and Structures 2015, 21(5), pp 565-595. doi: 10.12989/was.2015.21.5.565.

[53] Aly, A.M. Vibration control of high-rise buildings for wind: a robust passive and active tuned mass damper. Smart Structures and Systems 2014. Vol 13 (3), pp 473-500. doi: 10.12989/sss.2014.13.3.473.

[54] Lu, Z., Wang, Z., Zhou, Y. \& Lu, X. Nonlinear dissipative devices in structural vibration control: A review. Journal of Sound and Vibration 2018. 423, pp 18-49. doi:10.1016/j.jsv.2018.02.052

[55] Lu, Z., Wang, Z., Masri, S.F. \& Lu, X. Particle impact dampers: Past, present and future. Struct. Control Health Monit. 2017, e2058. doi:10.1002/stc.2058

[56] Lu., Z., Chen, X., Zhang, D. \& Dai, K. Experimental and analytical study on the performance of particle tuned mass dampers under seismic excitation. Earthquake Engineering and Structural Dynamics 2016. Vol 46(5), pp 697-714. doi: 10.1002/eqe.2826

[57] Lu, Z., Wang. D., Masri, S.F. \& Lu, X. An experimental study of vibration control of wind-excited high-rise buildings using particle tuned mass dampers. Smart Structures and Systems 2016. Vol 18 (1), pp 93-115. doi: 10.12989/sss.2016.18.1.093

[58] El-Khoury, O. \& Adeli, H. Recent Advances on Vibration Control of Structures Under Dynamic Loading. Arch Comput Methods Eng 2013. 20, pp 353-360. doi: 10.1007/s11831013-9088-2

[59] Gutierrez Soto \& M., Adeli, H. Recent advances in control algorithms for smart structures and machines. Expert Systems 2017. 34:e12205. doi:10.1111/exsy.12205 
[60] Li, Z. \& Adeli, H. New discrete-time robust $\mathrm{H}_{2} / \mathrm{H}_{\infty}$ algorithm for vibration control of smart structures using linear matrix inequalities. Engineering Application of Artificial Intelligence 2016. Vol 55, pp 47-57. doi: 10.1016/j.engappai.2016.05.008

[61] Gutierrez Soto, M. \& Adeli, H. Vibration Control of Smart Base-Isolated Irregular buildings using neural dynamic optimization model and replicator dynamics. Engineering Structures 2018. Vol 156:1, pp 322-336. doi: 10.1016/j.engstruct.2017.09.037

[62] Gutierrez Soto, M. \& Adeli, H. Multi-agent replicator controller for sustainable vibration control of smart structures. Journal of Vibroengineering 2017. Vol 19:6, pp 43004322. doi: 10.215959jve.2017.18924

[63] Adeli, H. \& Kim, H. Wavelet-Hybrid Feedback-Least mean Square Algorithm for Robust Control of Structures. Journal of Structural Engineering 2004. Vol 130 (1). doi: 10.1061/(ASCE)0733-9445(2004)130:1(128)

[64] Etedali, S. \& Tavakoli, S. PD/PID Controller Design for Seismic Control of High-Rise Buildings Using Multi-Objective Optimization: A Comparative Study with LQR Controller. Journal of Earthquake and Tsunami 2017. Vol 11(3). doi: 10.1142/S1793431117500099.

[65] Etedali, S., Zamani, A. \& Tavakoli, S. A GBMO-based PI $\lambda \mu$ controller for vibration mitigation of seismic-excited structures. Automation in Construction 2018, 87, pp 1-12. doi: 10.1016/j.autcon.2017.12.005.

[66] Karami, K., Manie, S., Ghafouri, K. \& Nagarajaiah, S. Nonlinear structural control using integrated DDA/ISMP and semi-active tuned mass damper. Engineering Structures 2019, 181, pp 589-604. Doi: 10.1016/j.engstruct.2018.12.059.

[67] Zelleke, D. H. \& Matsagar, V. A. Energy-based predictive algorithm for semi-active tuned mass dampers. Structural Design of Tall and Special Buildings 2019. 28 (12) e1626. doi: doi.org/10.1002/tal.1626.

[68] Kim, H. \& Adeli, H. Hybrid control of irregular steel highrise building structures under seismic excitations. Int. J. Numer. Meth. Engng 2005, 63, pp 1757-1774. doi: 10.1002/nme.1336

[69] Kim, H. \& Adeli, H. Hybrid Control of Smart Structures Using a Novel Wavelet-Based Algorithm. Computer-Aided Civil and Infrastructure Engineering 2005. Vol 20, pp 7-22. doi:10.1111/j.1467-8667.2005.00373.x

[70] Fisco, N.R. \& Adeli, H. Smart structures: Part I - Active and semi-active control. Scientia Iranica 2011. Vol 18(3), pp275-284. doi: 10.1016/j.scient.2011.05.034 
[71] Fisco, N.R. \& Adeli, H. Smart structures: Part II - Hybrid control systems and control strategies. Scientia Iranica 2011. Vol 18(3), pp 285-295. doi:10.1016/j.scient.2011.05.035

[72] Kareem, A. Mitigation of Wind Induced Motion of Tall Buildings. Journal of Wind Engineering and Industrial Aerodynamics 1983, 11, Amsterdam pp 273-284. doi:10.1016/0167-6105(83)90106-x.

[73] Burton, M., Kwok, K. C. S. \& Abdelrazaq, A. Wind-Induced Motion of Tall Buildings: Designing for Occupant Comfort. International Journal of High-Rise Buildings 2015. doi:10.1061/9780784413852.

[74] Gilani, A. S., Miyamoto, H. K. \& Determan, L. Seismic rehabilitation of historic reinforced concrete buildings with fluid viscous dampers: Two case studies. 8th US National Conference on Earthquake Engineering 2006, April 18, 2006 - April 22. 2006, San Francisco, CA, United states, Earthquake Engineering Research Institute. pp. 9899-9908.

[75] CSI (Computer and Structures Inc.). SAP2000 v19.0.0 Integrated Finite Element Analysis and Design of Structures, 2016. CSI, Berkeley.

[76] Chopra, A.K. Dynamics of Structures. Theory and Applications to Earthquake Engineering. 2012, Prentice Hall, $4^{\text {th }}$ ed

[77] CEN. Eurocode 8: Design of structures for earthquake resistance. Part 1: General rules, seismic actions and rules for buildings. 2004, BS EN 1998-1-4:2004

\section{Nomenclature}

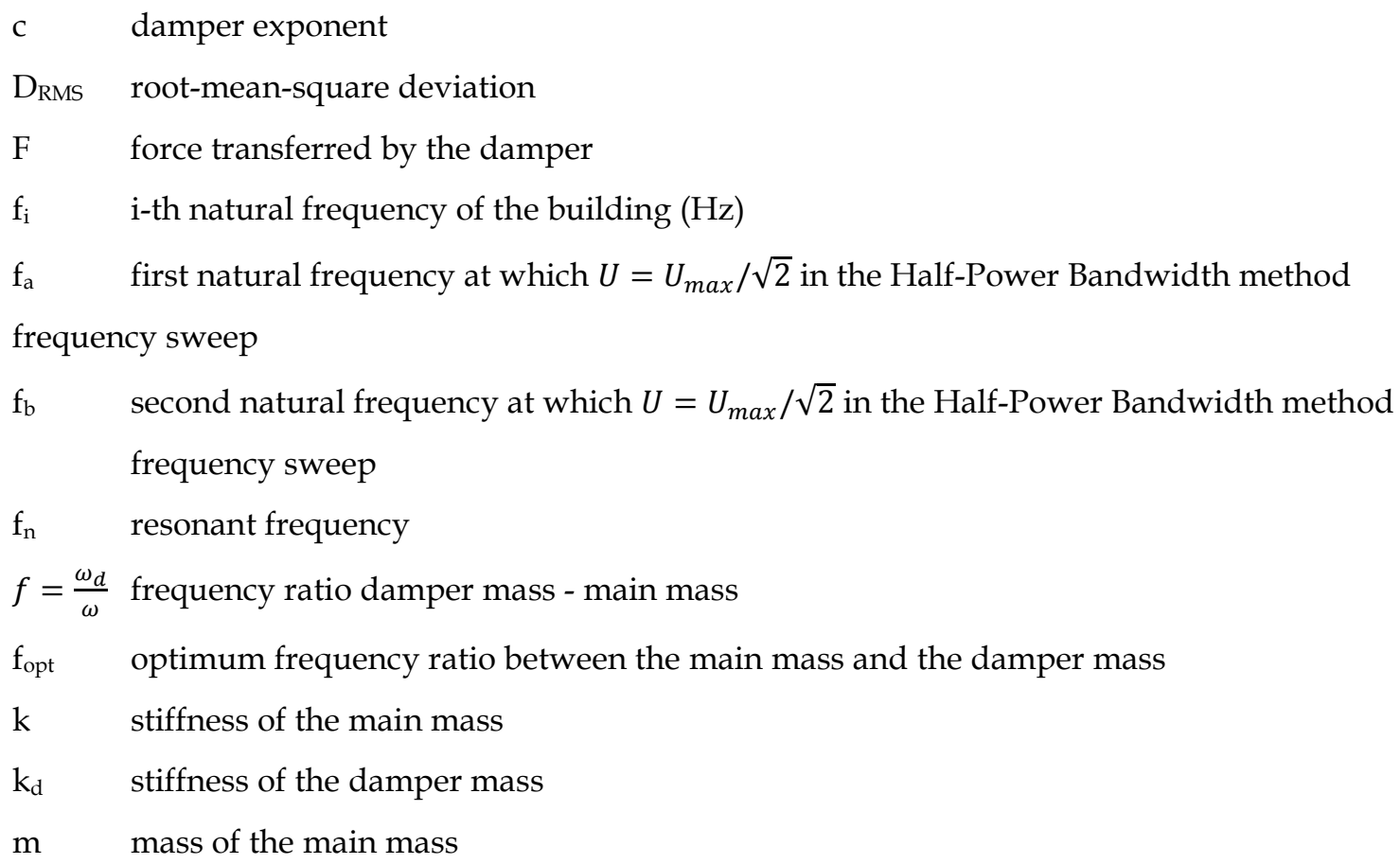




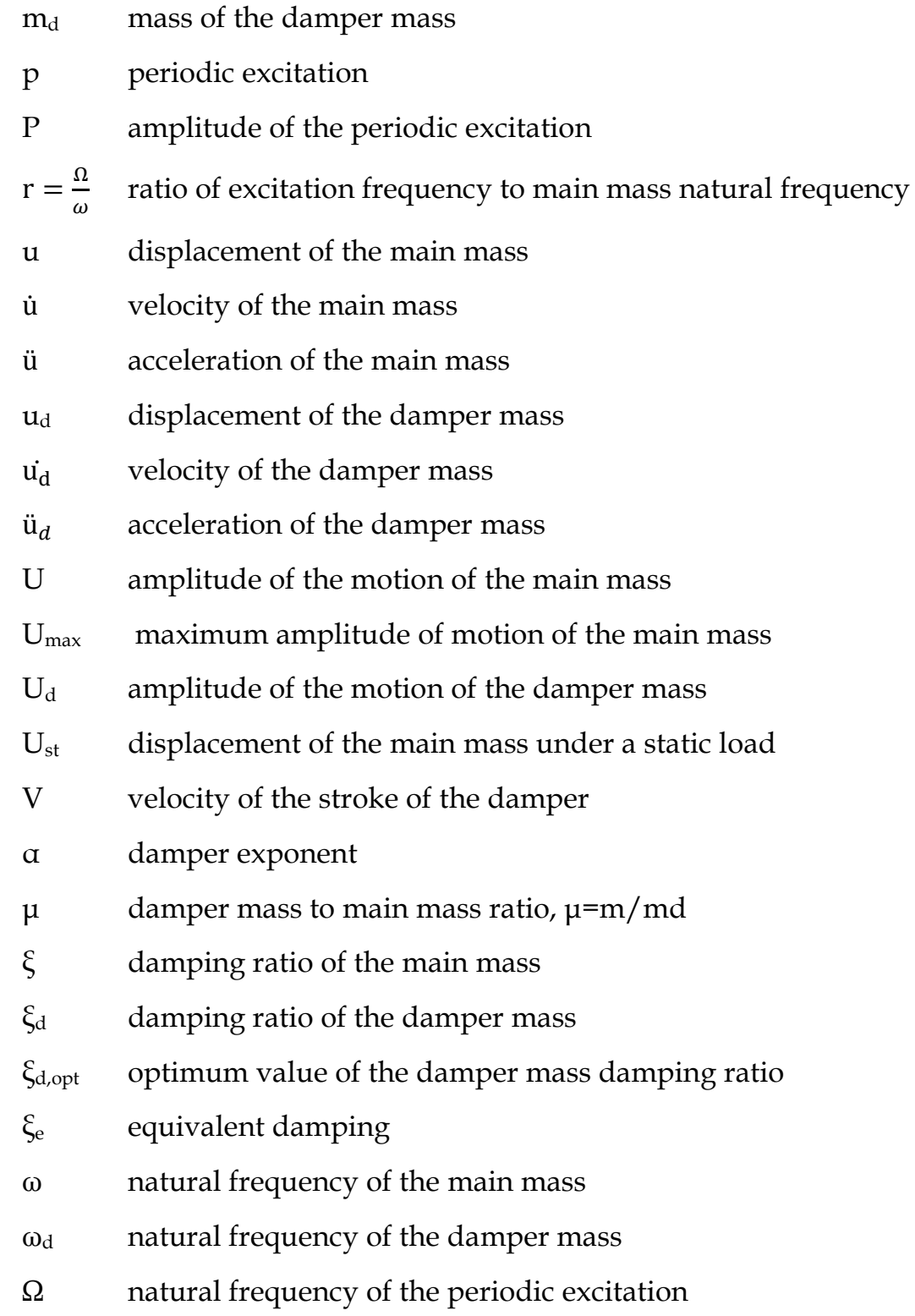

